\title{
Energy and environmental performance assessment of R744 booster supermarket refrigeration systems operating in warm climates
}

\author{
Gullo, Paride; Elmegaard, Brian; Cortella, Giovanni
}

Published in:

International Journal of Refrigeration

Link to article, DOI:

10.1016/j.jirefrig.2015.12.016

Publication date:

2016

Document Version

Peer reviewed version

Link back to DTU Orbit

Citation (APA):

Gullo, P., Elmegaard, B., \& Cortella, G. (2016). Energy and environmental performance assessment of R744 booster supermarket refrigeration systems operating in warm climates. International Journal of Refrigeration, 64, 61-79. https://doi.org/10.1016/j.ijrefrig.2015.12.016

\section{General rights}

Copyright and moral rights for the publications made accessible in the public portal are retained by the authors and/or other copyright owners and it is a condition of accessing publications that users recognise and abide by the legal requirements associated with these rights.

- Users may download and print one copy of any publication from the public portal for the purpose of private study or research.

- You may not further distribute the material or use it for any profit-making activity or commercial gain

- You may freely distribute the URL identifying the publication in the public portal 


\title{
Energy and Environmental Performance Assessment of R744 Booster Supermarket Refrigeration Systems operating in Warm Climates
}

\author{
Paride Gullo $^{a}$, Brian Elmegaard $^{b}$ and Giovanni Cortella $^{c}$ \\ ${ }^{a}$ University of Udine, Department of Electrical, Management and Mechanical Engineering (DIEG), via \\ delle Scienze 206, 33100 Udine, Italy, gullo.paride@spes.uniud.it \\ ${ }^{b}$ DTU Technical University of Denmark, Department of Mechanical Engineering (Thermal Energy \\ Section), Nils Koppels Allé 403, 2800 Kgs. Lyngby, Denmark, be@mek.dtu.dk \\ ${ }^{c}$ University of Udine, Department of Electrical, Management and Mechanical Engineering (DIEG), via \\ delle Scienze 206, 33100 Udine, Italy, giovanni.cortella@uniud.it
}

\author{
Corresponding author: \\ - Paride Gullo \\ - Email address: gullo.paride@spes.uniud.it \\ - Tel: +390432558022 \\ - Fax: +390432558027
}

\begin{abstract}
:
This paper presents a theoretical comparison among different commercial refrigeration systems in terms of annual energy consumption and environmental impact. Eight configurations were studied: a R744/R134a cascade refrigeration system (baseline), a conventional and an improved R744 booster system, two R744 booster solutions with dedicated mechanical subcooling, a R744 booster with parallel compression and two solutions which combined the parallel compression and the mechanical subcooling. The evaluation was based on the weather data in Valencia (Spain) and in Athens (Greece), as well as on the running modes of a conventional European supermarket. A transition zone, which occurred between subcritical and transcritical operations, was adopted.

The results showed that all the enhanced configurations may achieve a comparable energy saving to the one of the baseline in both the selected locations. Furthermore, they allow reducing the Total Equivalent Warming Impact (TEWI) by at least $9.6 \%$ beside the cascade solution.
\end{abstract}

Keywords:

Annual Energy Consumption, $\mathrm{CO}_{2}$, Compressor Efficiency, Dedicated Mechanical Subcooling, Parallel Compression, TEWI.

\section{Nomenclature}

\section{Roman symbols}

$B R A$

British Refrigeration Association

$C B$

Conventional Booster Refrigeration System

$C O P$

Coefficient of Performance

$C S$

Cascade Refrigeration System

EES

Engineering Equation Solver 
GWP Global Warming Potential, $\mathrm{kg}_{\mathrm{CO}_{2}} \cdot \mathrm{kg}_{\text {refrigerant }}^{-1}$

HFC Hydrofluorocarbon

HP High Pressure

HS High Stage

HT High Temperature

IB Improved Booster Refrigeration System

$L \quad$ Annual leakage rate, $\mathrm{kg}_{\mathrm{S} \cdot \mathrm{year}^{-1}}$

$L S \quad$ Low stage

LT Low Temperature

MS7 Booster Refrigeration System with dedicated Mechanical Subcooling down to $7{ }^{\circ} \mathrm{C}$

MS15 Booster Refrigeration System with dedicated Mechanical Subcooling fixed to $15{ }^{\circ} \mathrm{C}$

MT Medium Temperature

$m \quad$ Refrigerant charge, $\mathrm{kg}$

$n \quad$ System operating lifetime, year

$p \quad$ Pressure, bar

$P C \quad$ Booster Refrigeration System with Parallel Compression

PCMS Booster Refrigeration System with Parallel Compression and Mechanical Subcooling $t \quad$ Temperature, ${ }^{\circ} \mathrm{C}$

TEWI Total Equivalent Warming Impact, ton $_{\mathrm{CO}_{2}}$

\section{Greek symbols}

$\alpha \quad$ Recycling factor, $\%$

$\beta \quad$ Indirect emission factor, $\mathrm{kg}_{\mathrm{CO}_{2}} \cdot \mathrm{kWh}^{-1}$

$\Delta \quad$ Difference

$\eta \quad$ Efficiency

$\chi \quad$ Amount of saturated vapour sucked by the auxiliary compressor, $\mathrm{kg} \cdot \mathrm{s}^{-1}$

\section{Subscripts and superscripts}

appr Approach

$A U X$ Auxiliary compressor

cc Cooling Capacity

cond Condenser

el Electrical

ext External

gc Gas cooler

global Global

int Intermediate pressure

MAX Maximum

out Outlet

SUB Subcooler 


\section{Introduction}

Carbon dioxide (R744) is a natural refrigerant which is capable of providing similar or even better performance than synthetic refrigerants when employed in subcritical conditions. From the thermophysical point of view, it shows lower viscosity and higher latent heat, thermal conductivity, density, volumetric cooling capacity and specific heat than HFCs (Ge and Tassou, 2011). The interest in $\mathrm{CO}_{2}$ as a refrigerant has been increasing rapidly in the last few years thanks to its advantageous thermo-physical properties, non-flammability, non-toxicity, cheapness and negligible Global Warming Potential (GWP). Due to its low critical temperature $\left(30.98{ }^{\circ} \mathrm{C}\right)$, transcritical operations take place as soon as the outdoor temperature exceeds a threshold level, which can be as low as $15{ }^{\circ} \mathrm{C}$ (Girotto et al., 2004), and high operating pressures can be easily reached. As a main consequence, high exergy destruction rates can be associated with the expansion valve of a transcritical $\mathrm{CO}_{2}$ machine, which cause a large decline in its performance. As proposed by Fazelpour and Morosuk (2014), a solution to reduce such inefficiencies is to utilize an economizer downstream of the gas cooler. This concept is, in some extent, similar to the one of using a mechanical subcooling loop presented in this paper. Furthermore, in such operating conditions, an optimal value of high pressure, which maximizes the Coefficient of Performance (COP), has to be identified as a function of the gas cooler outlet temperature (Kim et al., 2004).

On the one hand, R744 has been being widely utilized as the secondary working fluid of indirect systems in which it can perform at the most favourable conditions, namely distant from the critical temperature and at acceptable operating pressures. On the other hand, its use as the main refrigerant at high external temperatures still needs to be further studied, evaluating all the aspects which involve thermodynamic, environmental and economic analyses.

In spite of these drawbacks, $\mathrm{CO}_{2}$ is a promising working fluid in different applications such as commercial refrigeration solutions, which are extremely energy-intensive systems characterized by a large direct environmental impact (i.e. refrigerant leakages). Since $\mathrm{CO}_{2}$ performs much worse than synthetic refrigerants in warm weathers, it is important to identify any improvement to accomplish at least similar energy consumption and thus similar indirect contributions to climate changes. The solutions to this issue include both the aspects of energy saving (e.g. closed display cabinets) and of energy efficiency (e.g. improvement of refrigeration systems, condenser fans with variable speed motors, etc.). As far as the direct emissions are concerned, carbon dioxide can reduce them drastically since its GWP is insignificant.

Cascade refrigeration systems are efficient solutions even in warm climates. In such configurations, R744 is usually employed in the low stage circuit and thus it always operates in subcritical conditions. Its use in the lower cascade system allows decreasing pumps power input and pipes size, as well as it features good heat transfer properties (Ge and Tassou, 2011). The refrigerant flowing in the high stage can be chosen among different fluids, both natural (R717, R290, R1270) and synthetic ones (R134a, R404A). Due to the flammability and/or the toxicity of the former and to the high GWP of the R400 series and in accordance with the regulation currently in force (European Commission, 2014), R134a is a good candidate to be used in upper cascade systems with cooling capacity over $40 \mathrm{~kW}$. Nevertheless, it is worth remarking that European Union has been pushing towards the use of natural refrigerants and that many countries have levied taxies on HFCs purchase (e.g. Spain) and/or promoted the spread of eco-friendly solutions (e.g. Belgium).

\subsection{Literature review}

Ge and Tassou (2011) carried out a sensitivity analysis of the main parameters which affect the performance of a R744 booster cycle over the range of outdoor temperatures from 25 to $40{ }^{\circ} \mathrm{C}$. The results showed that the optimal gas cooler pressure can be determined as a function of the isentropic 
efficiency of the high stage compressors rack, the outdoor temperature and the effectiveness of the internal heat exchanger located downstream of the gas cooler.

A comparison in terms of both annual energy consumption and costs between a $\mathrm{CO}_{2}$ refrigeration system and a direct expansion solution using R404A was made by Girotto et al. (2004). They concluded that the solution using the natural refrigerant has $10 \%$ higher power consumption than the other one when both of them are run in the North of Italy. The lower energy saving can be attributed to the cooling load at medium temperature (MT) since the system at low temperature (LT) points out similar performance to the one of the equivalent R404A system. The authors also proposed some possible enhancements, such as decreasing the approach temperature of the gas cooler, using two-stage compression for the MT system and sucking the vapour from the liquid receiver.

As for the possible improvements of the conventional refrigeration system, several solutions have been suggested. One of the most interesting technologies is the adoption of a dedicated mechanical subcooling. Thornton et al. (1994) proved the existence of an optimal subcooling temperature which is mainly influenced by the temperature at which the heat of condensation is rejected into the external heat sink and the one of the heat source from which vaporization heat is extracted.

The experimental investigation by Qureshi and Zubair (2013) showed experimentally that a subcooling loop can improve both the cooling capacity and the exergetic efficiency of a basic system. Llopis et al. (2015a) evaluated the potential enhancements which could be fulfilled by utilizing a subcooling cycle on the part of both a conventional $\mathrm{CO}_{2}$ system and $\mathrm{CO}_{2}$ cycle with double-stage compression and intercooling. The former operated at evaporating temperatures of 5 ${ }^{\circ} \mathrm{C}$ and $-5{ }^{\circ} \mathrm{C}$, whereas a low temperature equal to $-30{ }^{\circ} \mathrm{C}$ was chosen for the latter. In both cases the outdoor temperature ranged from $20{ }^{\circ} \mathrm{C}$ to $35{ }^{\circ} \mathrm{C}$. The authors studied the use of R290, R1270, R1234yf, R161, R152a and R134a as the refrigerant for the subcooler loop concluding that the achievable improvements are independent of the selected working fluid. At the outdoor temperature of $30^{\circ} \mathrm{C}$ and with a degree of subcooling of $5{ }^{\circ} \mathrm{C}$, the use of R134a allows increasing COP by $9.5 \%$ at $5{ }^{\circ} \mathrm{C}$, by $13.7 \%$ at $-5{ }^{\circ} \mathrm{C}$ and by $13.1 \%$ at $-30{ }^{\circ} \mathrm{C}$.

Hafner and Hemmingsen (2015) estimated an energy saving varying from $11 \%$ to $28 \%$ related to a R744 unit with a R290 dedicated mechanical subcooling loop beside a R404A direct expansion system. The evaluation was attained taking into account weather conditions in several cities located all over the world.

Parallel compression is another propitious solution which allows enhancing the performance of a conventional $\mathrm{CO}_{2}$ refrigeration system by compressing a part or the entire amount of vapour generated in the liquid receiver from the intermediate pressure to the high one.

The importance of the intermediate pressure as a key parameter of the optimization procedure was underlined by Chiarello et al. (2010) and by Minetto et al. (2005). Its optimum value is mainly influenced by the evaporator temperature, as demonstrated by Sarkar and Agrawal (2010). They also claimed that the parallel compression is a more effective solution to improve the efficiency of a single-stage $\mathrm{CO}_{2}$ cycle than both the configuration with two-stage compression and flash gas bypass and the one with parallel compression and subcooler. The assessment was fulfilled considering gas cooler outlet temperatures from 30 to $60{ }^{\circ} \mathrm{C}$ and the evaporating temperatures of $-45,-20$ and 5 ${ }^{\circ} \mathrm{C}$.

Chiarello et al. (2010) performed an experimental campaign and implemented a theoretical model in order to prove the obtainable enhancements. The experimental apparatus, even though it showed interesting results, was mainly run in subcritical conditions.

A test rig was built by Minetto et al. (2005) to prove the feasibility of this solution and the possibility to overcome the technological issues associated with it, such as the lubricant oil return. The authors also showed theoretically that a $\mathrm{CO}_{2}$ booster system with parallel compression can accomplish good results in terms of both cooling capacities and COPs over a conventional one. 
They claimed that the intermediate pressure can be controlled by a variable-frequency drive as a function of the swept volume ratio of the compressors.

Da Ros (2005) compared a conventional single-stage R744 cycle operating at the evaporating temperature of $-10{ }^{\circ} \mathrm{C}$ with a solution with parallel compression and a system with double-stage compressor. The author took into account both a constant and a freely variable pressure difference between the gas cooler and the liquid receiver. In all the evaluated cases, the system with the twostage compressor performs better than the other ones.

An alternative to the system with auxiliary compressor is the one which uses a single compressor with vapour injection at intermediate pressure. This solution was compared experimentally to that with dedicated auxiliary compressor by Bella and Kaemmer (2011). The assessment was conducted ranging the intermediate and the high pressures and keeping the evaporating temperature equal to $10{ }^{\circ} \mathrm{C}$. They found out that, even though this solution is able to achieve good efficiencies, the system with dedicated compressor is preferable in terms of both evaluated COP and practical constraints, such as vibrations and ease of the intermediate pressure control.

The annual energy consumption evaluation for a supermarket located in Bari (Italy) carried out by Minetto et al. (2014) points out that the solution with parallel compression can attain a large energy saving in comparison with a conventional system.

A theoretical model was implemented by Chesi et al. (2014) to find out the best operating conditions as well as the effect of the liquid separator efficiency, the intermediate pressure and the compressors volumetric flow ratio on the performance of the overall system. The authors asserted that the largest enhancements in cooling capacity arise at gas cooler pressures different from those at which maximum COPs occur. An experimental investigation was also implemented considering different high pressures, gas cooler outlet temperatures and evaporating temperatures in order to evaluate the main parameters which influence the system under investigation. Both the analyses confirmed that the use of an auxiliary compressor can improve the performance of a conventional $\mathrm{CO}_{2}$ refrigeration system. Pressure drop in the suction line, unintentional superheating and a faulty separation between vapour and liquid within the receiver can worsen the performance of the real cycle strongly.

Gullo et al. (2015) compared from the energetic, exergetic and exergoeconomic point of view a system with parallel compression with a basic solution. The analyses were based on a system with a cooling capacity of $100 \mathrm{~kW}$. The cooling medium temperatures were varied from 30 to $50{ }^{\circ} \mathrm{C}$, whereas the evaporating temperature was kept equal to $-10{ }^{\circ} \mathrm{C}$. The outcomes showed that, beside the single-stage refrigeration system, the improved system can reduce the total power input on average by $18.7 \%$ leading to an increase in total purchased equipment cost by $23.4 \%$. Furthermore, a decrement in the irreversibilities of the throttling valve by about $50 \%$ was also reached.

Hafner et al. (2014a) made a comparison among different R744 refrigeration configurations operating in warm climates at different operating conditions. Considering the case with the evaporator cooling capacity equal to $100 \mathrm{~kW}$, the configuration with dedicated mechanical loop and fixed subcooler outlet temperature along with the solution which combines the parallel compression and the ejector show the highest COPs over the outdoor temperatures range varying from 30 to 42 ${ }^{\circ} \mathrm{C}$. The solution with liquid receiver and parallel compressor presents slightly lower COPs than the solution without flash tank and auxiliary compression in all the evaluated cases. Only transcritical operations and single-stage evaporation systems were taken into account.

A comparison in terms of annual energy consumption for four different Chinese locations was presented by Hafner et al. (2014b). It could be concluded that a system with dedicated mechanical subcooling can achieve an energy saving by $16 \%$ over a R404A system.

Polzot et al. (2015) compared the performance of three different booster refrigeration solutions with that of a R744/R134a cascade refrigeration system. The authors studied a conventional booster solution and a solution using a water tank as a cold storage with and without parallel compression. The simulation was carried out considering the weather trend in Genoa (Italy), which is 
characterized by a mild climate. The results obtained suggested that a comparable energy saving to that of the cascade refrigeration system can be accomplished by employing an auxiliary compressor.

An experimental campaign was conducted by Sawalha et al. (2015) in five Swedish supermarkets. The outcomes underlined that large improvements can be realized by using a subcooler and by removing the flash gas generated in the intermediate pressure liquid receiver. Further enhancements can be reached by reducing the external superheating and by increasing both the evaporating temperatures and the compressors overall efficiency.

Sanz-Kock et al. (2014) collected experimental measurements regarding a $\mathrm{R} 134 \mathrm{a} / \mathrm{CO}_{2}$ cascade refrigeration system varying the evaporating temperature from -40 to $-30{ }^{\circ} \mathrm{C}$ and the condensing temperature from 30 to $50{ }^{\circ} \mathrm{C}$, respectively. The experimental setup exhibited cooling capacities from 4.5 to $7.5 \mathrm{~kW}$. Several parameters were taken into account, such as performance of the compressors, temperature difference in the cascade condenser, cooling capacity and COP. At the constant LS evaporating temperature of $-30{ }^{\circ} \mathrm{C}$, an average decrement in COP by $18 \%$ is obtained for each increase in the condensing temperature of the high stage (HS) circuit by $10{ }^{\circ} \mathrm{C}$. On the other hand, keeping HS condensing temperature at $40{ }^{\circ} \mathrm{C}$, the COP brings down on average by $12 \%$ for each decrease in the LS evaporating temperature by $5{ }^{\circ} \mathrm{C}$. Furthermore, the authors found out that the LS condensing temperature does not influence COP significantly. Cooling capacity was observed to be more dependent on the LS evaporating temperature than on the HS condensing temperature. The experimental results by Souza et al. (2015) confirmed that COP of such solution goes up with decrease in the $\mathrm{CO}_{2}$ compressor operating frequency.

The main target of this paper is to follow up the energy improvements that a R744 booster refrigeration system may fulfil by adopting a dedicated mechanical subcooling and/or an auxiliary compressor. A conventional $\mathrm{CO}_{2}$ booster system, an improved one with reduced gas cooler approach and minimum condensing temperatures, two $\mathrm{CO}_{2}$ booster system with dedicated mechanical subcooling, a booster with parallel compression and two $\mathrm{CO}_{2}$ booster solutions which combine the parallel compression and a subcooling loop are investigated. The annual energy consumption and the environmental impact in terms of TEWI of all the aforementioned configurations are compared with those of a $\mathrm{CO}_{2} / \mathrm{R} 134 \mathrm{a}$ cascade system (baseline), considering the weather trends in Valencia (Spain) and in Athens (Greece). In section 2 the methods including the modelling approach and the assumptions are presented, whereas the results are shown in the following section. Finally, the computed outcomes are compared with the other works and the main conclusions are stated in section 4.

\subsection{Investigated solutions}

A cascade system consists of two circuits (LS and HS) which interact with each other by using the so-called cascade condenser. The vaporization of the refrigerant in the high temperature stage takes place as a consequence of the heat rejection into the refrigerant flowing in the LS loop. The cascade condenser, in fact, operates as a condenser for the LS circuit and as an evaporator for the HS one under an appropriate temperature difference between the two selected working fluids. In the case of commercial refrigeration plants, the HS loop has some additional evaporators which are used to cool down chilled food display cabinets and cold rooms.

In this study, a cascade refrigeration system (Fig. 1) in which R134a and R744 flow respectively through the HS circuit and the LS one was considered as the baseline. In such circumstances, carbon dioxide always operates in subcritical conditions.

Fig. 1 - Schematic of a cascade refrigeration system. 
Unlike the cascade refrigeration system, R744 booster system uses carbon dioxide in both MT and LT display cabinets. A low stage compressors rack behaves as a booster in order to rise the refrigerant pressure. The heat exchanger at high pressure acts as a condenser at low outdoor temperatures, otherwise it operates as a gas cooler in transcritical conditions. In the latter case, ingoing $\mathrm{CO}_{2}$ undergoes a reduction in temperature without involving no phase change. The outgoing fluid from the gas cooler/condenser is throttled and split into its vapour and liquid components within the liquid receiver. The vapour is then isenthalpically expanded to the medium evaporating pressure by means of an additional expansion valve and compressed along with the mass flow rates exiting the LS compressors and the MT display cabinets to the high pressure.

Fig. 2 refers to a typical layout of a conventional booster system for commercial refrigeration applications.

Fig. 2 - Schematic of a conventional $\mathbf{R 7 4 4}$ booster refrigeration system.

The configuration with dedicated mechanical subcooling represents an interesting solution in order to drop the energy consumption of a R744 refrigeration systems which are run in warm climates (Hafner and Hemmingsen, 2015; Hafner et al., 2014a; Hafner et al., 2014b; Llopis et al., 2015a). Such solution, which is schematised in Fig. 3, includes a vapour-compression refrigeration unit cooling down $\mathrm{CO}_{2}$ leaving the gas cooler/condenser. This leads to a decrease in the refrigerant quality entering the liquid receiver and thus to a performance enhancement. Furthermore, the optimal gas cooler pressure is also reduced in comparison with the conventional configuration allowing to bring down the energy consumption of the overall system. In the present paper, a mechanical subcooling loop using R290 as the refrigerant was taken into account, which began operating as soon as transition conditions took place.

\section{Fig. 3 - Schematic of R744a refrigeration system with dedicated mechanical subcooling.}

Fig. 4 compares a conventional booster system (dotted line) with a booster solution with dedicated mechanical subcooling (solid line) in a $\log (p)$ - $h$ diagram. The difference is represented by the thermodynamic transformation indicated as $2-3$, which describes the subcooling process before $\mathrm{CO}_{2}$ enters the high pressure (HP) expansion valve $(3-4)$. On the contrary, the refrigerant exiting the gas cooler/condenser is directly throttled $(2-4$ ') in a conventional booster solution.

\section{Fig. 4 - $\log (p)$-h diagram of $R 744$ booster refrigeration systems with and without dedicated mechanical subcooling.}

The amount of vapour which is produced due to the HP expansion valve increases as the external temperature rises. This leads to an increment in the amount of refrigerant which has to be compressed from the medium pressure to the high one, implying a growth in the energy consumption associated with the high stage compressors (especially during summertime). Fig. 5 shows this phenomenon taking into account the configuration which will be called "improved booster" (IB) in this study. As explained in section 2.1, IB refers to a $\mathrm{CO}_{2}$ booster system with a minimum condensing temperature of $9{ }^{\circ} \mathrm{C}$ and gas cooler and condenser approach temperatures 
equal to 2 and $3 \mathrm{~K}$, respectively. The outcomes underline as, in transcritical operations, the mass flow rate of the flash gas (point 5 in Fig. 2) was on average equal to $45 \%$ of the total mass flow rate. Fig. 5 also points out that both the total and the vapour mass flow rate increased suddenly at temperatures over $38{ }^{\circ} \mathrm{C}$ due to the high gas cooler outlet temperature and thus to the high quality of the refrigerant going into the liquid receiver. The amount of vapour became equal to $50 \%$ of the refrigerant total mass flow rate at the external temperature of $40{ }^{\circ} \mathrm{C}$.

Fig. 5 - Total mass flow rate and flash gas mass flow rate of R744 improved booster refrigeration system (IB) operating in transcritical conditions $\left(t_{\mathrm{MT}}=-10{ }^{\circ} \mathrm{C}, \mathbf{t}_{\mathrm{LT}}=-35{ }^{\circ} \mathrm{C}\right)$.

A solution to this problem is to adopt an additional compressor (Fig. 6) on the purpose of sucking either a part or the entire amount of vapour from the intermediate pressure liquid receiver to the gas cooler pressure. As suggested by Chiarello et al. (2010), Minetto et al. (2005) and Sarkar and Agrawal (2010), in this case the overall system has to be optimized in terms of both the gas cooler pressure and the intermediate one.

Fig. 6 - Schematic of a R744 booster refrigeration system with parallel compression.

In this paper, in order to guarantee a suitable minimum mass flow rate for the auxiliary compressor, the latter was run as soon as transition conditions were fulfilled. The thermodynamic cycle of a booster system with parallel compression is described in $\log (p)$ - $h$ diagram in Fig. 7.

Fig. 7 - $\log (p)$-h diagram of $R 744$ booster refrigeration systems with parallel compression.

The use of a mechanical subcooler loop allows lessening the energy consumption of a conventional $\mathrm{CO}_{2}$ refrigeration machine. This solution can be combined with the parallel compression in order to derive the benefits associated with both systems starting from the transition conditions (Fig. 8).

Fig. 8 - Schematic of a R744 booster refrigeration system which combines the parallel compression and the mechanical subcooling.

\section{Methods}

\subsection{Case studies}

The calculations were based on the conditions of a typical European supermarket, as presented by EMERSON Climate Technologies (2010). The common running modes for all of the evaluated solutions are summarized in Table 1. In EMERSON Climate Technologies (2010), LT was set to $35^{\circ} \mathrm{C}$ for the R404A centralized direct expansion solution (baseline) and to $-32{ }^{\circ} \mathrm{C}$ for the booster system. The reason for this difference lies in the better $\mathrm{CO}_{2}$ performance during the vaporization process than that of R404A (Girotto et al., 2004). Since the estimation of these benefits is quite 
difficult, the authors preferred considering more general operating conditions, which were represented by R404A centralized direct expansion solution for LT and by the cascade system for MT. Furthermore, the superheating was split into two parts: a useful superheating, which took place within the evaporators, and an external one, which arose in the suction line.

\begin{tabular}{|ccc|}
\hline Table 1 - Operating conditions in common with all the evaluated systems. \\
\hline MT load & 97 & $\mathrm{~kW}$ \\
\hline LT load & 18 & $\mathrm{~kW}$ \\
\hline MT & -10 & ${ }^{\circ} \mathrm{C}$ \\
\hline LT & -35 & ${ }^{\circ} \mathrm{C}$ \\
\hline Useful superheating & 5 & $\mathrm{~K}$ \\
\hline External superheating & 5 & $\mathrm{~K}$ \\
\hline Condenser/Gas cooler fan power & 4.5 & $\mathrm{~kW}_{\mathrm{el}}$ \\
\hline MT evaporator fans, lights, defrost & 10 & $\mathrm{~kW}_{\mathrm{el}}$ \\
\hline LT evaporator fans, lights, defrost & 4 & $\mathrm{~kW}_{\mathrm{el}}$ \\
\hline
\end{tabular}

Table 2 shows the specific running modes for the different systems under investigation and the acronym used from now on to indicate the different selected solutions. The approach temperature in a heat exchanger can be defined as the difference between the temperature of the outgoing hot fluid and the one of the ingoing cold fluid. An "improved" booster (IB) solution was proposed in addition to the conventional configuration to investigate the reduction effect of both the gas cooler/condenser approach temperature and the minimum condensing one.

The intermediate pressure of CB, IB, MS7 and MS15 was kept constant since its influence on the performance is almost negligible, as demonstrated by Ge and Tassou (2011). 
Table 2 - Specific operating conditions of the evaluated systems.

\begin{tabular}{|c|c|c|c|c|c|c|c|c|}
\hline & $\begin{array}{l}\text { Cascade } \\
\text { refrigeration } \\
\text { system } \\
\text { (CS) }\end{array}$ & $\begin{array}{l}\text { Conventional } \\
\text { R744 booster } \\
\text { refrigeration } \\
\text { system } \\
\text { (CB) }\end{array}$ & $\begin{array}{l}\text { Improved } \\
\text { R744 booster } \\
\text { refrigeration } \\
\text { system } \\
\text { (IB) }\end{array}$ & $\begin{array}{c}\mathrm{R} 744 \\
\text { booster with } \\
\text { subcooler } \\
\text { outlet } \\
\text { temperature } \\
\text { varying } \\
\text { down to } 7 \\
{ }^{\circ} \mathrm{C} \\
\text { (MS7) }\end{array}$ & $\begin{array}{c}\text { R744 } \\
\text { booster with } \\
\text { subcooler } \\
\text { outlet } \\
\text { temperature } \\
\text { equal to } 15 \\
{ }^{\circ} \mathrm{C} \\
\text { (MS15) }\end{array}$ & $\begin{array}{c}\text { R744 } \\
\text { booster } \\
\text { with } \\
\text { parallel } \\
\text { compression } \\
\text { (PC) }\end{array}$ & $\begin{array}{l}\text { R744 booster } \\
\text { with } \\
\text { parallel } \\
\text { compression } \\
\text { and } \\
\text { dedicated } \\
\text { mechanical } \\
\text { subcooling } \\
\text { using R290 } \\
\text { (PCMS290) }\end{array}$ & $\begin{array}{l}\text { R744 booster } \\
\text { with } \\
\text { parallel } \\
\text { compression } \\
\text { and dedicated } \\
\text { mechanical } \\
\text { subcooling } \\
\text { using R1270 } \\
\text { (PCMS1270) }\end{array}$ \\
\hline $\begin{array}{l}\text { Minimum condensing temperature } \\
\qquad\left[{ }^{\circ} \mathbf{C}\right]\end{array}$ & 25 & 10 & 9 & 9 & 9 & 9 & 9 & 9 \\
\hline $\begin{array}{l}\text { Approach temperature of the } \\
\text { condenser } \\
{[\mathrm{K}]}\end{array}$ & 10 & 10 & 3 & 3 & 3 & 3 & 3 & 3 \\
\hline $\begin{array}{l}\text { Approach temperature of the gas } \\
\text { cooler } \\
{[\mathrm{K}]}\end{array}$ & - & 5 & 2 & 2 & 2 & 2 & 2 & 2 \\
\hline $\begin{array}{l}\text { Temperature difference of the } \\
\text { cascade condenser } \\
{[\mathrm{K}]}\end{array}$ & 5 & - & - & - & - & - & - & - \\
\hline $\begin{array}{l}\text { Intermediate pressure } \\
\text { [bar] }\end{array}$ & - & 35 & 35 & 35 & 35 & Optimized & Optimized & Optimized \\
\hline
\end{tabular}


The following additional assumptions were made:

1. pressure drop was neglected and all the expansion valves were treated as isenthalpic devices;

2. refrigerant of the subcooling loop underwent an internal superheating of $5 \mathrm{~K}$ and condenser fan power of the mechanical subcooling loop was set to $1 \mathrm{~kW}$;

3. selected working fluids for the subcooling loop were R290 for MS7, MS15 and PCMS290 and R1270 for PCMS1270;

4. approach temperature of the condenser of the mechanical subcooling loop added up to $8 \mathrm{~K}$;

5. approach temperature of the evaporator of the mechanical subcooling loop for MS7 amounted to $5 \mathrm{~K}$;

6. with respect to MS15, PCMS290 and PCMS1270, it was assumed that the compressors of the respective subcooling loop operated at as high evaporating temperature as possible in accordance with their corresponding operating envelope;

7. no heat transfer into the surroundings was considered.

\subsection{Simulation model}

Models of the cycles were implemented in Engineering Equation Solver (EES) (F-Chart Software, 2015a), which were based on the fundamental thermodynamic equations at steady state.

As previously explained, a $\mathrm{CO}_{2}$ booster refrigeration system operates in subcritical conditions when outdoor temperature is low enough, whereas transcritical operations occurs at high external temperatures. In order to improve its performance, it is necessary to define a transition zone which arises at intermediate outdoor temperatures and which depends on the ability of the condenser to reject heat into the surroundings. A procedure similar to the one adopted by Cecchinato et al. (2007) was used to determine the conditions in which transcritical operations took place. As sketched in Fig. 9, four operational zones were defined. Zone I referred to the subcritical conditions in which, independently of the external temperature, the condensing temperature was kept equal to its minimum value, in accordance with Table 2. As a result of this, the energy consumption was constant.

The shift from Zone I to Zone II depended on the approach temperature of the condenser and on the outdoor temperature. Since in both Zone I and Zone II a degree of subcooling of $2 \mathrm{~K}$ was selected, it occurred at values of external temperatures over $4{ }^{\circ} \mathrm{C}$ for IB, MS7, MS15, PC, PCMS290 and PCMS1270, whereas it took place over $-2{ }^{\circ} \mathrm{C}$ for CB. Starting from such conditions, the system entered the subcritical zone in which the condensing temperature was ranged according to the external temperature (Zone II). The R744 condenser outlet temperature could be evaluated as follows:

$$
t_{\text {out }, \text { cond }}=t_{\text {ext }}+\Delta T_{\text {appr, cond }}
$$

The transition zone (Zone III) was the one where the system moved gradually from the subcritical conditions to the transcritical ones. Conforming to the chosen condenser approach temperatures (Table 2), these conditions arose at external temperatures higher than $17{ }^{\circ} \mathrm{C}$ for IB, MS7, MS15, PC, PCMS290 and PCMS1270 and higher than $10{ }^{\circ} \mathrm{C}$ for CB. According to Cecchinato et al. (2007), Zone III could be defined by identifying an upper and a lower limit in terms of high pressure and gas cooler/condenser outlet temperature. In accordance with both such boundary conditions and the external temperature, the high pressure heat exchanger varied its working conditions linearly (segment A - B in Fig. 9). The condenser outlet temperature and the condensing 
one at the point $\mathrm{A}$ in Fig. 9 were set to 20 and $22{ }^{\circ} \mathrm{C}$, respectively. The gas cooler outlet temperature and the upper limit of the high pressure, indicated as the point B in Fig. 9, were chosen equal to $29^{\circ} \mathrm{C}$ and 75 bar (Table 3 and Table 4), respectively. In these running modes, the approach temperature of the gas cooler/condenser decreased from $3 \mathrm{~K}$ (point A in Fig. 9) for IB, MS7, MS15, PC, PCMS290 and PCMS1270 to $2 \mathrm{~K}$ (point B in Fig. 9) and from $10 \mathrm{~K}$ (point A in Fig. 9) to $5 \mathrm{~K}$ (point B in Fig. 9) for CB. The system operated along the conditions represented by the segment A $\mathrm{B}$ in Fig. 9, following for IB, MS7 and MS15 the below equations:

$$
\begin{gathered}
t_{\text {out }, \mathrm{gc} / \mathrm{cond}}=0.9 \cdot t_{\mathrm{ext}}+4.7(2) \\
p_{g c / \mathrm{cond}}=1.6633 \cdot t_{\text {out }, g c / \text { cond }}+26.763
\end{gathered}
$$

and

$$
\begin{aligned}
& t_{\text {out }, \text { gc } / \text { cond }}=0.6429 \cdot t_{\text {ext }}+13.571 \\
& p_{g c / \text { cond }}=1.6633 \cdot t_{\text {out }, g c / \text { cond }}+26.763
\end{aligned}
$$

for CB.

Furthermore, this control strategy allowed reducing the degree of subcooling of the condenser/gas cooler from $2 \mathrm{~K}$ to a null value.

Transcritical conditions (Zone IV) took place at outdoor temperatures over $27{ }^{\circ} \mathrm{C}$ for IB, MS7, MS15, PC, PCMS290 and PCMS1270 and over $24{ }^{\circ} \mathrm{C}$ for CB. As previously mentioned, in Zone IV an optimal gas cooler pressure had to be evaluated as a function of the external temperature (Kim et al., 2004).

Fig. 9 - Definition of the operating zones for the R744 refrigeration booster systems under

\begin{tabular}{|c|c|c|c|c|c|}
\hline Zone & $\begin{array}{c}\mathbf{t}_{\text {ext }} \\
{\left[{ }^{\circ} \mathbf{C}\right]}\end{array}$ & $\begin{array}{c}\mathbf{t}_{\text {out,condMAX }} \\
{\left[{ }^{\circ} \mathrm{C}\right]}\end{array}$ & $\begin{array}{c}\mathbf{t}_{\text {condMAX }} \\
{\left[{ }^{\circ} \mathbf{C}\right]}\end{array}$ & $\begin{array}{c}\mathbf{t}_{\text {out,gcMAX }} \\
{\left[{ }^{\circ} \mathbf{C}\right]}\end{array}$ & $\begin{array}{c}\mathbf{p}_{\mathrm{gc}, \mathrm{Max}} \\
\text { [bar] }\end{array}$ \\
\hline I & $t_{\mathrm{ext}} \leq-2$ & 8 & 10 & - & - \\
\hline II & $-2<t_{\mathrm{ext}} \leq 10$ & 20 & 22 & - & - \\
\hline III & $10<t_{\mathrm{ext}} \leq 24$ & - & - & 29 & 75 \\
\hline IV & $24<\mathrm{t}_{\mathrm{ext}} \leq 40$ & - & - & 45 & 106 \\
\hline
\end{tabular}
investigation.

Table 3 for CB and Table 4 for IB, MS7, MS15, PC, PCMS290 and PCMS1270 summarize the different selected operating zones. 


\section{Table 4 - Operating zone for IB, MS7, MS15, PC, PCMS290 and PCMS1270.}

\begin{tabular}{|cccccc|}
\hline Zone & $\begin{array}{c}\mathbf{t}_{\text {ext }} \\
{\left[{ }^{\circ} \mathbf{C}\right]}\end{array}$ & $\begin{array}{c}\mathbf{t}_{\text {out,condMAX }} \\
{\left[{ }^{\circ} \mathbf{C}\right]}\end{array}$ & $\begin{array}{c}\mathbf{t}_{\text {condMAx }} \\
{\left[{ }^{\circ} \mathbf{C}\right]}\end{array}$ & $\begin{array}{c}\mathbf{t}_{\text {out,gcMAx }} \\
{\left[{ }^{\circ} \mathbf{C}\right]}\end{array}$ & $\begin{array}{c}\mathbf{p}_{\text {gc,MAX }} \\
{[\mathbf{b a r}]}\end{array}$ \\
\hline I & $\mathrm{t}_{\mathrm{ext}} \leq 4$ & 7 & 9 & - & - \\
\hline II & $4<\mathrm{t}_{\mathrm{ext}} \leq 17$ & 20 & 22 & - & - \\
\hline III & $17<\mathrm{t}_{\mathrm{ext}} \leq 27$ & - & - & 29 & 75 \\
\hline IV & $27<\mathrm{t}_{\mathrm{ext}} \leq 40$ & - & - & 42 & 106 \\
\hline
\end{tabular}

Two different approaches were taken into account for MS7 and MS15:

a) R744 subcooler outlet temperature could be reduced down to $7^{\circ} \mathrm{C}$, which is a typical value of minimum condenser outlet temperature for a $\mathrm{CO}_{2}$ booster system;

b) R744 subcooler outlet temperature was set equal to $15^{\circ} \mathrm{C}$.

As for PCMS290 and PCMS1270, a constant subcooler outlet temperature equal to $15{ }^{\circ} \mathrm{C}$ was chosen. Furthermore, the chosen compressor using R1270 presented a maximum evaporation temperature of $5{ }^{\circ} \mathrm{C}$, which was twice as low as that of the compressor employing R290.

It is worth remarking that MS7, MS15, PC, PCMS290 and PCMS1270 perform in exactly the same way as IB in subcritical conditions.

Table 5 sums up the independent variables which were adopted during the optimization procedures of the R744 booster refrigeration systems under investigation. The DIRECT algorithm Method was implemented in case of two or more optimization variables, otherwise the Golden Section search Method was applied (F-Chart Software, 2015b). In all cases, the minimization of the total energy consumption was chosen as the objective function.

Table 5 - Independent variables for the optimization procedures of the R744 booster refrigeration systems under investigation.

\begin{tabular}{|ccc|}
\hline & Transition conditions & Transcritical conditions \\
\hline CB and IB & - & $\mathrm{p}_{\mathrm{gc}}$ \\
\hline MS7 & $\mathrm{t}_{\text {out,SUB }}$ & $\mathrm{p}_{\mathrm{gc}}, \mathrm{t}_{\mathrm{out}, \text { SUB }}$ \\
\hline MS15 & - & $\mathrm{p}_{\mathrm{gc}}$ \\
\hline PC & $\mathrm{p}_{\text {int, }} \chi$ & $\mathrm{p}_{\mathrm{gc}}, \mathrm{p}_{\mathrm{int}}, \chi$ \\
\hline PCMS290 & $\mathrm{p}_{\text {int }}$ & $\mathrm{p}_{\mathrm{gc}}, \mathrm{p}_{\mathrm{int}}$ \\
\hline PCMS1270 & $\mathrm{p}_{\text {int }}$ & $\mathrm{p}_{\mathrm{gc}}, \mathrm{p}_{\mathrm{int}}$ \\
\hline
\end{tabular}

A "global efficiency" for the compressors was defined as the ratio of the power input calculated at the isentropic conditions and the power input declared by the manufacturers. The global efficiencies of the compressors using R134a and R744 were derived from BITZER Software (BITZER, 2015) as a function of the pressure ratio (Table 6 and Table 7), whereas Dorin Software (Dorin, 2015) was utilized to obtain R290 and R1270 compressors performance. All the chosen compressors were semi-hermetic reciprocating ones and all their suggested technological constraints were respected. 


\section{Table 6 - Compressors global efficiencies in subcritical and transition conditions.}

Configuration

\section{Compressor global efficiency}

$$
\eta_{\text {global }, R 134 a}=-0.0053 \cdot\left(\frac{p_{H P, R 134 a}}{p_{M T, R 134 a}}\right)^{2}+0.0674 \cdot\left(\frac{p_{H P, R 134 a}}{p_{M T, R 134 a}}\right)+0.4802
$$

CS

$$
\eta_{\text {global }, R 744}=0.0111 \cdot\left(\frac{p_{M T, R 744}}{p_{L T, R 744}}\right)^{2}-0.0793 \cdot\left(\frac{p_{M T, R 744}}{p_{L T, R 744}}\right)+0.803
$$

CB, IB, MS7,

MS15, PC,

PCMS290 and

PCMS1270

$$
\eta_{\text {globalLS,R744 }}=-0.0012 \cdot\left(\frac{p_{M T, R 744}}{p_{L T, R 744}}\right)^{2}-0.0087 \cdot\left(\frac{p_{M T, R 744}}{p_{L T, R 744}}\right)+0.6992
$$

Auxiliary compressor for PC

$$
\eta_{\text {globalAUX,R744 }}=-0.172 \cdot\left(\frac{p_{H P, R 744}}{p_{\text {int }, R 744}}\right)^{2}+0.7095 \cdot\left(\frac{p_{H P, R 744}}{p_{\text {int }, R 744}}\right)-0.0373
$$

Auxiliary compressor for PCMS290 and PCMS1270

\begin{tabular}{|c|c|}
\hline $\begin{array}{c}\text { R290 Subcooler } \\
\text { loop }\end{array}$ & $\eta_{\text {global }, R 290}=-0.0939 \cdot\left(\frac{p_{H T, R 290}}{p_{L T, R 290}}\right)^{2}+0.4966 \cdot\left(\frac{p_{H T, R 290}}{p_{L T, R 290}}\right)-0.0449$ \\
\hline $\begin{array}{c}\text { R1270 Subcooler } \\
\text { loop }\end{array}$ & $\eta_{\text {global }, R 1270}=-0.047 \cdot\left(\frac{p_{H T, R 1270}}{p_{L T, R 1270}}\right)^{2}+0.3442 \cdot\left(\frac{p_{H T, R 1270}}{p_{L T, R 1270}}\right)+0.0299$ \\
\hline
\end{tabular}




\section{Table 7 - Compressors global efficiencies in transcritical conditions.}

CB, IB, MS7,

Configuration Compressor global efficiency

$$
\eta_{\text {global }, R 134 a}=-0.0053 \cdot\left(\frac{p_{H P, R 134 a}}{p_{M T, R 134 a}}\right)^{2}+0.0674 \cdot\left(\frac{p_{H P, R 134 a}}{p_{M T, R 134 a}}\right)+0.4802
$$

CS

$$
\begin{gathered}
\eta_{\text {global }, R 744}=0.0111 \cdot\left(\frac{p_{M T, R 744}}{p_{L T, R 744}}\right)^{2}-0.0793 \cdot\left(\frac{p_{M T, R 744}}{p_{L T, R 744}}\right)+0.803 \\
\eta_{\text {globalHS }, R 744}=-0.0021 \cdot\left(\frac{p_{H P, R 744}}{p_{M T, R 744}}\right)^{2}-0.0155 \cdot\left(\frac{p_{H P, R 744}}{p_{M T, R 744}}\right)+0.7325
\end{gathered}
$$

MS15, PC,

PCMS290 and

PCMS1270

$$
\eta_{\text {globalLS,R744 }}=-0.0012 \cdot\left(\frac{p_{M T, R 744}}{p_{L T, R 744}}\right)^{2}-0.0087 \cdot\left(\frac{p_{M T, R 744}}{p_{L T, R 744}}\right)+0.6992
$$

In this paper the results were compared in three different ways. The first comparison referred to all $\mathrm{CO}_{2}$ refrigeration systems. The other ones compared all the evaluated solutions in terms of annual energy consumption and TEWI assuming $\mathrm{CO}_{2} / \mathrm{R} 134 \mathrm{a}$ cascade refrigeration system as the baseline.

\subsection{Outdoor temperatures}

Valencia (Spain) and Athens (Greece) were identified as the warm climates locations in which implementing the aforesaid comparisons. Their different outdoor temperature distributions were obtained by using Meteonorm (Remund et al., 2014).

Fig. 10 - Number of hours per year at different outdoor temperatures in Athens (Greece) and Valencia (Spain).

According to Fig. 10, the outdoor temperature was higher than $27{ }^{\circ} \mathrm{C}$ for about $11 \%$ of the time in Athens and for about $6 \%$ in Valencia. In these conditions, transcritical operations occurred for CB, IB, MS7, MS15, PC, PCMS290 and PCMS1270. On the other hand, transcritical operations for the conventional booster took place at external temperatures higher than $24{ }^{\circ} \mathrm{C}$, which arose for more than $21 \%$ of the time in Athens and for about $14 \%$ in Valencia. 
Transition conditions took place for CB, IB, MS7, MS15, PC, PCMS290 and PCMS1270 at outdoor temperatures greater than $17{ }^{\circ} \mathrm{C}$, which occurred for about $49 \%$ of the time in Athens and for about $50 \%$ in Valencia. As regards CB, it was run in transcritical conditions for about $57 \%$ of the time in Athens and for about $61 \%$ in Valencia.

This outcome points out the importance associated with the choice of a suitable optimisation strategy for the transition zone.

\subsection{Total Equivalent Warming Impact}

The Total Equivalent Warming Impact (TEWI) is a parameter which assesses both the direct and the indirect emissions of greenhouse gases. The former are due to refrigerant leaks, whereas the latter are due to $\mathrm{CO}_{2}$ emissions associated with the process of electricity generation. It is defined as (BRA, 2006):

$$
\begin{gathered}
T E W I=T E W I_{\text {direct }}+T E W I_{\text {indirect }} \\
T E W I_{\text {direct }}=G W P \cdot L \cdot n+G W P \cdot m \cdot(1-\alpha) \\
T E W I_{\text {indirect }}=E \cdot \beta \cdot n
\end{gathered}
$$

As far as the evaluated solutions are concerned, the below assumptions were made:

- the GWP of R134a, R744, R1270 and R290 were selected equal to 1430, 1, 1.8 and 3, respectively (EMERSON Climate Technologies, 2010; The Australian Institute of Refrigeration, 2012);

- an annual leakage rate for the systems using $\mathrm{CO}_{2}$ of $15 \%$ was chosen (EMERSON Climate Technologies, 2010; Shilliday, 2012), whereas it added up to 5\% for the mechanical subcooling cycles since they were supposed to be completely confined in the machinery room (Llopis et al., 2015b);

- the operating life of all the selected systems was evaluated equal to 10 years (EMERSON Climate Technologies, 2010; Shilliday, 2012);

- the R134a charge in the HS circuit of the cascade refrigeration system was chosen equal to 2 $k g_{R 134 a} \cdot k W_{c c}^{-1}$ (EMERSON Climate Technologies, 2010);

- the $\mathrm{CO}_{2}$ charge in the LS circuit of the cascade refrigeration system was set to $1 \mathrm{~kg}_{R 744}$. $k W_{c c}^{-1}$

- the $\mathrm{CO}_{2}$ charge in all the booster refrigeration systems was chosen equal to $1.2 \mathrm{~kg}_{R 744}$. $k W_{c c}^{-1}$ (Shilliday, 2012);

- the R290 charge and that of the R1270 were selected equal to $70 \mathrm{~kg}$;

- $95 \%$ of the refrigerant was assumed to be recycled (EMERSON Climate Technologies, 2010);

- the $\mathrm{CO}_{2}$ emission due to the electricity generation added up to $0.241 \mathrm{~kg}_{\mathrm{CO}_{2}} \cdot \mathrm{kWh}^{-1}$ (Llopis et al., 2015b) in Valencia and to $0.720 \mathrm{~kg}_{\mathrm{CO}_{2}} \cdot \mathrm{kWh}^{-1}$ (International Energy Agency, 2013) in Athens.

\section{Results}


In this section a comparison in terms of performance evaluation and optimal gas cooler pressure among all the investigated R744 refrigeration systems was firstly reported. Then, the evaluation of

\subsection{Performance comparison among the evaluated $\mathbf{R} 744$ refrigeration systems}

The decrement in the gas cooler/condenser approach temperature of a R744 booster system would drive to the reduction in optimal high pressure and thus to the increment in the overall system performance. The additional adoption of a mechanical subcooling would allow attaining a further drop in the optimal discharge pressure and a growth in the specific refrigerating effect promoted by the decrease in the quality of the refrigerant entering the liquid receiver. According to Fig. 11, MS15 showed a reduction in quality by about $64.9 \%$ in comparison with IB in transcritical conditions. It could also be noticed that the former was characterized by a decreasing trend, whereas MS7 had a growing one. The reason for this outcome lies in the fact that the state point representing the subcooler outlet conditions for MS15 shifted along an isothermal transformation, which drives to a reduction in the quality of the refrigerant as the high pressure (and therefore the outdoor temperature) goes up. Vice versa, MS7 underwent the opposite phenomenon since the temperature was not fixed. In transition operations, the refrigerant quality for IB exhibited on average $38.6 \%$ higher values than those showed by MS15. $\mathrm{CO}_{2}$ quality of MS15 presented an average value of 0.14 at external temperatures ranging from $18{ }^{\circ} \mathrm{C}$ to $40{ }^{\circ} \mathrm{C}$. MS7 pointed out quality values on average $63.6 \%$ lower than those shown by IB. CB, IB and MS7 also had a sudden increase in quality as transcritical conditions occurred, which became even more marked at very high external temperatures. This outcome underlines further the need for the adoption of a subcooler loop for refrigeration systems operating in warm weathers. It is worth noticing that PCMS290 and PCMS1270 had a similar behaviour to that showed by MS15.

Fig. 11 - Quality of $\mathbf{R 7 4 4}$ entering the liquid receiver as a function of the outdoor temperature in transition and transcritical conditions $\left(t_{\mathrm{MT}}=-10{ }^{\circ} \mathrm{C}, \mathrm{t}_{\mathrm{LT}}=-35{ }^{\circ} \mathrm{C}\right)$.

In Fig. 11, the results associated with $\mathrm{CB}$ were presented starting from $\mathrm{t}_{\mathrm{ext}}=11{ }^{\circ} \mathrm{C}$ as the transition operations occurred at lower outdoor temperatures than in the cases of IB, MS7 and MS15, conforming to Table 3.

The trend of the temperature at the subcooler outlet regarding MS7, as pointed out in Fig. 13, was approximately constant for external temperatures up to $27{ }^{\circ} \mathrm{C}$ and then it began increasing as transcritical conditions approached. As soon as these running modes arose, this trend became more significant. This result can be justified taking into account that the adoption of the mechanical subcooling leads to two benefits. The former is associated with the reduction in refrigerant temperature entering the liquid receiver, which implies a growth in the refrigerating effect, whereas the second benefit is associated with the reduction in the high pressure, which allows dropping the energy consumption. Since no optimal high pressure could be accomplished in the transition region, the system needed to achieve the highest degree of subcooling in order to be capable of enhancing its performance in such conditions. On the contrary, the system could draw with both the benefit associated with the subcooling and the one associated with the reduction in gas cooler pressure as soon as transcritical conditions took place. As a result of this, the system was able to achieve the optimal conditions at higher subcooler outlet temperatures than in the previous case. 
Fig. 12 - Subcooler outlet temperature as a function of the outdoor temperatures in transition and transcritical conditions $\left(\mathrm{t}_{\mathrm{MT}}=\mathbf{- 1 0}{ }^{\circ} \mathrm{C}, \mathrm{t}_{\mathrm{LT}}=-35^{\circ} \mathrm{C}\right)$.

Fig. 13 highlights the high reduction in the mass flow rate of the flash gas exiting the liquid receiver related to the use of the mechanical subcooling. At very high outdoor temperature, the mass flow rate sucked by the auxiliary compressor was about five times higher than the one of the solutions which combined the parallel compression and a mechanical subcooler loop.

Fig. 13 - Flash gas mass flow rate of PC and PCMS290 as a function of the outdoor temperature in transition and transcritical conditions $\left(t_{\mathrm{MT}}=-10{ }^{\circ} \mathrm{C}, \mathrm{t}_{\mathrm{LT}}=-35{ }^{\circ} \mathrm{C}\right)$.

As aforementioned, the intermediate pressure becomes a key parameter for the optimization procedure in case of the use of an auxiliary compressor (Chiarello et al., 2010; Sarkar and Agrawal, 2010; Minetto et al., 2005). The results obtained indicated that, when both the parallel compression and the mechanical subcooler loop were run, the influence of the intermediate pressure was almost negligible and the performance of the system was mainly affected by the high pressure since the subcooler outlet temperature was kept constant. The reason for this result lies in the low quality of the refrigerant flowing into the liquid receiver thanks to the presence of the subcooler. Fig. 14 shows this outcome distinctly underling as the intermediate pressure of PCMS290 (and that of PCMS1270) tended to be as low as possible in accordance with the technological constraints of the flash tank. Furthermore, as for PC, it was possible to notice a sudden increase in the optimum intermediate pressure as soon as the transcritical operations took place. This result could be associated with the increment in the amount of vapour which had to be sucked at high external temperatures. In these conditions, in fact, the intermediate pressure had to be risen in order to be capable of decreasing the electrical consumption of the additional compressor. The average value of the optimal intermediate pressure in the range of outdoor temperatures from $18{ }^{\circ} \mathrm{C}$ to $27{ }^{\circ} \mathrm{C}$ was equal to 40 bar. The liquid receiver pressure was as low as 44.51 bar at $28{ }^{\circ} \mathrm{C}$ and it reached an average value equal to $48.13 \mathrm{bar}$ at external temperatures from $29^{\circ} \mathrm{C}$ to $40{ }^{\circ} \mathrm{C}$.

Fig. 14 - Optimal intermediate pressure as a function of the outdoor temperature in transition and transcritical conditions $\left(\mathrm{t}_{\mathrm{MT}}=\mathbf{- 1 0}{ }^{\circ} \mathrm{C}, \mathrm{t}_{\mathrm{LT}}=\mathbf{- 3 5}{ }^{\circ} \mathrm{C}\right)$.

A further result associated with PC was that the percentage of vapour sucked by the additional compressor was almost constant and equal to $99.38 \%$ of the total flash gas mass flow rate in both transition conditions and transcritical ones.

Fig. 15 compares the optimal gas cooler pressure values which were achieved by all the evaluated $\mathrm{CO}_{2}$ booster solutions in transcritical conditions.

Fig. 15 - Optimal gas cooler pressure of the evaluated solutions as a function of the outdoor temperature in transcritical conditions $\left(t_{\mathrm{MT}}=-10{ }^{\circ} \mathrm{C}, \mathbf{t}_{\mathrm{LT}}=-35^{\circ} \mathrm{C}\right)$.

In accordance with Table $3, \mathrm{CB}$ started operating in transcritical conditions at $\mathrm{t}_{\mathrm{ext}}=25^{\circ} \mathrm{C}$, whereas the other evaluated systems reached them at $t_{\mathrm{ext}}=28{ }^{\circ} \mathrm{C}$ (Table 4). Furthermore, MS7 and MS15 
had a similar trend in optimal gas cooler pressure. IB was characterized by values on average about $6 \%$ higher than those of both the systems with mechanical subcooling. This difference went up with the increment in the outdoor temperature, underling that these solutions are even more efficient at very high temperatures, in accordance with Llopis et al. (2015a). The maximum level of gas cooler pressure showed in Fig. 15 was due to the operating envelopes of the selected compressors. Furthermore, this outcome was markedly connected to the $\mathrm{CO}_{2}$ quality values of $\mathrm{CB}$ at temperatures over $37^{\circ} \mathrm{C}$ (Fig. 11). The values associated with PC were on average $4.2 \%$ lower than those showed by IB, whereas PCMS1270 achieved on average a reduction by $5.3 \%$. It is important to notice that, due to technological limits of the selected R1270 compressor, the performance of this system was penalised by a lower maximum evaporating temperature in comparison with the R290 compressor. PCMS290 exhibited the lowest optimal gas cooler pressures, which were on average $6.3 \%$ smaller than the ones associated with IB.

\subsection{Performance comparison among the evaluated refrigeration systems}

Fig. 16 makes a comparison in terms of COP among all the selected solutions. It was possible to notice that below the outdoor temperatures of $14{ }^{\circ} \mathrm{C}$, all the solutions (except for CB) performed better or similarly than CS. As soon as transition operations arose and thus the mechanical subcooling and/or the auxiliary compressor began operating, MS15, PC, PCMS290, PCMS1270 and MS7 had the best COPs among the alternatives to CS. Although they could obtain the benefits associated with the subcooling and/or those of the parallel compression, their COP could not exceed the one of the baseline at high outdoor temperatures. PCMS290 and MS7 tended to outperform PCMS1270 at high external temperatures due to a lower maximum evaporating temperature of the subcooler using R1270. It could be claimed that, in order to achieve a satisfying energy saving, either a large subcooling or the combination of the parallel compression with the mechanical subcooling was necessary for a $\mathrm{CO}_{2}$ booster refrigeration system which was run in warm climates. $\mathrm{PC}$ was also an optimal alternative especially for external temperatures up to $33^{\circ} \mathrm{C}$. In fact, at very high outdoor temperatures, the adoption of a mechanical subcooling was much more worthwhile than that of an auxiliary compressor.

Fig. 16 - COP of the selected solutions at outdoor temperatures from 0 to $40{ }^{\circ} \mathrm{C}\left(\mathrm{t}_{\mathrm{MT}}=-10{ }^{\circ} \mathrm{C}\right.$, $\left.\mathbf{t}_{\mathrm{LT}}=-\mathbf{3 5}{ }^{\circ} \mathrm{C}\right)$.

At the outdoor temperature of $28^{\circ} \mathrm{C}, \mathrm{CB}, \mathrm{IB}, \mathrm{MS} 7$ and MS15 exhibited a COP which added up to $1.19,1.33,1.52$ and 1.51 , respectively. At very high outdoor temperatures, the difference in COP between MS15 and MS7 brought down since the subcooler outlet temperatures in the latter case reached values close to $15{ }^{\circ} \mathrm{C}$.

In comparison with IB, MS15 and MS7 had on average about 23.2\% and $23.3 \%$ higher values of COP in transcritical conditions. The difference in performance was smaller in transition operations since the benefit associated with the optimal high pressure vanished. This implied that MS7 and MS15 could only obtain the advantage related to the increment in the refrigerating effect thanks to the drop in the refrigerant quality going into the liquid receiver. At these running conditions, IB highlighted on average 7.7\% and 6.2\% lower COP values than those exhibited by MS7 and MS15. These outcomes underlined the importance of the adoption of a mechanical subcooling loop for the $\mathrm{CO}_{2}$ booster refrigeration systems operating in warm weathers. It is important to notice that MS7 and PCMS290 were slightly penalised at outdoor temperatures ranging from $18{ }^{\circ} \mathrm{C}$ to $22{ }^{\circ} \mathrm{C}$ due to the operating envelope of the R290 compressor. A similar phenomenon occurred for PCMS1270 at external temperatures over $37^{\circ} \mathrm{C}$. In transition conditions, the difference in COPs between MS7 and 
MS15 was on average equal to $1.4 \%$. As transcritical conditions took place, it got negligible $(0.12 \%)$ since they had similar subcooler outlet temperatures. At outdoor temperatures over $27{ }^{\circ} \mathrm{C}$, the adoption of an auxiliary compressor led to an average enhancement of COP by $16 \%$ beside IB. PCMS1270 showed COPs similar to the ones of PCMS290 and MS7 and an increase in COP difference with the rise in the external temperature due to a lower maximum evaporating temperature of the subcooler in comparison with that using R290. PCMS290 had the highest COPs which were on average $25 \%$ higher than the ones presented by IB. In transition operations, PC, PCMS290 and PCMS1270 had an increase in COP respectively by 7.5\%, 8.2\% and 5.6\% beside IB. In all the evaluated cases, the effect of the system improvement was more appreciable as the outdoor temperature increases. Furthermore, PC featured higher COPs for external temperatures up to $33^{\circ} \mathrm{C}$ and thus it exhibited a more marked decreasing trend than the one associated with MS15.

The use of a mechanical subcooler can improve the performance of a conventional R744 booster system considerably. On the other hand, total investment costs would increase and the adoption of an operating strategy similar to that with variable subcooler outlet temperature (MS7) would make more difficult the control and the management of the overall system. As shown in Fig. 17, the required cooling capacity of the mechanical subcooling loop ranged from $12.9 \mathrm{~kW}$ to $67.5 \mathrm{~kW}$ for MS15, PCMS290 and PCMS1270 and from $24.1 \mathrm{~kW}$ to $67.9 \mathrm{~kW}$ for MS7. This means that the mechanical subcooler would have run at part load for most of the time. Setting the subcooler outlet temperature to a prefixed value would allow facilitating the control strategy of the overall system. Furthermore, the difference in the required cooling capacity on part of the subcooler was almost negligible at high outdoor temperatures, whereas it dropped in transition conditions due to lower required $\mathrm{CO}_{2}$ subcooler outlet temperature for MS7 beside MS15, PCMS290 and PCMS1270.

Fig. 17 - Required cooling capacity of the subcooler in transition and transcritical conditions

$$
\left(t_{\mathrm{MT}}=-10{ }^{\circ} \mathrm{C}, \mathrm{t}_{\mathrm{LT}}=-35^{\circ} \mathrm{C}\right) \text {. }
$$

Neither the trend of the cooling capacity nor the one of the compressor power input were presented since the former was constant and the latter had the same trend as that of COP.

\subsection{Comparison in terms of annual energy consumption}

The annual energy consumption of the selected solutions performing in Athens and Valencia are compared in Table 8. CB and IB consumed about 20\% and 5\% more energy than CS over the year, respectively. On the other hand, it was possible to achieve comparable energy consumption with that associated with CS by employing one of the other investigated solutions.

\section{Table 8 - Annual energy consumption [MWh] and percent difference [\%] in comparison with} CS.

\begin{tabular}{|cccccccc|}
\hline & CB & IB & MS7 & MS15 & PC & PCMS290 & PCMS1270 \\
\hline \multirow{2}{*}{ Athens } & 656.6 & 574.8 & 544.3 & 547.5 & 547.2 & 541.9 & 550.1 \\
& $(+20.2 \%)$ & $(+5.2 \%)$ & $(-0.4 \%)$ & $(+0.2 \%)$ & $(+0.2 \%)$ & $(-0.8 \%)$ & $(+0.7 \%)$ \\
\multirow{2}{*}{ Valencia } & 644.4 & 563.8 & 539.1 & 543.0 & 539.9 & 537.2 & 545.0 \\
& $(+19.2 \%)$ & $(+4.3 \%)$ & $(-0.2 \%)$ & $(+0.5 \%)$ & $(-0.1 \%)$ & $(-0.6 \%)$ & $(+0.8 \%)$ \\
\hline
\end{tabular}

\subsection{Comparison in terms of Total Equivalent Warming Impact}


The values of TEWI of the selected solutions are compared in Table 9. The assumptions made for the annual leakage rates related to R290, R1270 and R744 are susceptible of modifications depending on the system, its manufacturing and its lifetime. However, thanks to the negligible GWP of the previously mentioned refrigerants, the order of magnitude of the direct contributions to the TEWI exhibited by all the investigated $\mathrm{CO}_{2}$ configurations added up to about $10^{-4}$ of the global effect. On the other hand, the direct effect due to the refrigerant leaks associated with CS was respectively equal to $9.9 \%$ of the total TEWI in Athens and to $24.8 \%$ in Valencia.

Although R744 is characterized by a very low value of GWP, CB had a higher TEWI than CS in Athens due to its large energy consumption. The reduction in approach temperature of the gas cooler/condenser and in the minimum condensing temperature drove to a drop in terms of environmental impact in both the investigated cities. In fact, IB showed an average decrement in TEWI by $5.1 \%$ in Athens and by $21.6 \%$ in Valencia over CS. All the enhanced solutions featured lower TEWI than that of the baseline. This result could be associated with both a much lower direct environmental impact than CS and the insignificant difference in annual electricity consumption among them. Interesting results were obtained for both the systems with dedicated mechanical subcooling. As far as MS7 is concerned, its TEWI dropped by about 10.2\% in Athens and by 25\% in Valencia beside that of CS, whereas the total greenhouse gases emissions brought down on average by about $9.6 \%$ and by $24.4 \%$ for MS15. The lowest TEWI values were achieved by PCMS290, which were 10.6\% in Athens and 25.3\% in Valencia lower than those of the baseline. Similar values were found for PCMS1270 and PC, which were able to reduce TEWI by $24.2 \%$ and by $24.9 \%$ in the selected Spanish locality and by $9.2 \%$ and by $9.7 \%$ in the Greek one in comparison with CS.

It could be concluded that the adoption of MS15 allowed reducing the total greenhouse gases emissions by $420.6 t_{\mathrm{CO}_{2}}$ in Athens and by $423.6 t_{\mathrm{CO}_{2}}$ in Valencia over a period of time of 10 years. Considering MS7, these values were as high as $443.8 t_{\mathrm{CO}_{2}}$ and $432.9 t_{\mathrm{CO}_{2}}$, respectively. Furthermore, PC, PCMS290 and PCMS1270 led to a reduction in TEWI by $422.8,460.8$ and 402.1 $t_{\mathrm{CO}_{2}}$ in Athens and by 431.1, 437.5 and $418.9 t_{\mathrm{CO}_{2}}$ in Valencia over the plant lifetime.

\begin{tabular}{|c|c|c|c|c|c|c|c|}
\hline & CB & IB & MS7 & MS15 & PC & PCMS290 & PCMS1270 \\
\hline Athens & $\begin{array}{c}4727.6 \\
(+8.4 \%)\end{array}$ & $\begin{array}{l}4139.1 \\
(-5.1 \%)\end{array}$ & $\begin{array}{c}3919.1 \\
(- \\
10.2 \%)\end{array}$ & $\begin{array}{c}3942.4 \\
(-9.6 \%)\end{array}$ & $\begin{array}{c}3940.1 \\
(-9.7 \%)\end{array}$ & $\begin{array}{c}3902.1 \\
(-10.6 \%)\end{array}$ & $\begin{array}{l}3960.9 \\
(-9.2 \%)\end{array}$ \\
\hline Valencia & $\begin{array}{c}1553.3 \\
(-10.3 \%)\end{array}$ & $\begin{array}{c}1359.0 \\
(-21.6 \%)\end{array}$ & $\begin{array}{c}1299.6 \\
(- \\
25.0 \%)\end{array}$ & $\begin{array}{c}1308.9 \\
(-24.4 \%)\end{array}$ & $\begin{array}{c}1301.4 \\
(-24.9 \%)\end{array}$ & $\begin{array}{c}1295.0 \\
(-25.3 \%)\end{array}$ & $\begin{array}{c}1313.6 \\
(-24.2 \%)\end{array}$ \\
\hline
\end{tabular}

\section{Discussion and conclusions}

In this study, a comparative energy and environmental analysis among seven different commercial R744 refrigeration solutions has been performed. The outcomes obtained have been compared with those of a R744/R134a cascade refrigeration system (baseline). The running modes of a typical European supermarket, represented by a MT load of $97 \mathrm{~kW}$ at $-10{ }^{\circ} \mathrm{C}$ and a LT load of $18 \mathrm{~kW}$ at -35 ${ }^{\circ} \mathrm{C}$, have been selected. The evaluation has been based on the weather trends in Valencia (Spain) and in Athens (Greece). The power input of all the selected compressors has been evaluated by means of some manufacturers 'software. Furthermore, a transition zone, which allows the $\mathrm{CO}_{2}$ systems to move from the subcritical operations to the transcritical conditions progressively, has been designated. The performance of CB, IB and MS15 have been optimized in terms of gas cooler pressure in transcritical conditions, whereas the subcooler outlet temperature has been considered as 
an additional optimization variable for MS7. As regards PC, the optimization procedure has also involved the auxiliary compressor mass flow rate and the intermediate pressure in transition conditions. In transcritical operations, gas cooler pressure has become an additional optimization key parameter. Taking into account the solutions which integrates the parallel compression and the mechanical subcooling, its performance has been assessed as a function of the intermediate pressure in transition operations, whereas high pressure has also been considered in transcritical conditions.

The results show that either a large subcooling or the combination of the parallel compression with a mechanical subcooling is needed in order to accomplish comparable performance to the one of the $\mathrm{CO}_{2} / \mathrm{R} 134 \mathrm{a}$ cascade refrigeration system in both the evaluated locations. In fact, MS7 and PCMS290 exhibit similar energy consumption to that of the baseline in both the investigated weather conditions. Due to the technological constraints of R1270 compressor, PCMS1270 consumes more energy than MS15, MS7 and PCMS290.

As far as PC is concerned, the flash gas mass flow rate has a growing trend with the increment in the external temperature, which drives to a significant deterioration of its performance in hot climates. Furthermore, the auxiliary compressor should compress the total amount of vapour mass flow rate to accomplish the best performance in both transition conditions and transcritical ones. It is easy to deduce that this choice would entail the use of a large size compressor and therefore a rise in the total investment cost. A trade-off between the energetic and economic aspects related to the auxiliary compressor selection should be considered.

An additional benefit associated with the adoption of the subcooler and/or an auxiliary compressor is the reduction in the total environmental impact. This is mainly attributable to the achievement of the same annual consumption (and thus the same amount of indirect greenhouse gases emissions) as that exhibited by the cascade system, as well as to a significant decrement in the direct environmental impact thanks to the use of natural refrigerants. The reduction in TEWI of the enhanced solutions ranges from $9.2 \%$ to $25.3 \%$ beside the baseline.

The adoption of a subcooler loop presents some drawbacks, such as:

a) the investment cost of a $\mathrm{CO}_{2}$ booster system is $48 \%$ higher than the one of a $\mathrm{R} 404 \mathrm{~A}$ system (Shilliday, 2012) and the adoption of a dedicated mechanical subcooling would drive to a supplementary growth in it;

b) the subcooling loop has to be run at part load conditions for most of the time and a variable subcooler outlet temperature would make its control system difficult to be implemented.

The latter issue could be partly worked out by setting the $\mathrm{CO}_{2}$ subcooler outlet temperature to a fixed value. Furthermore, MS15 has similar results in terms of both energy consumption and TEWI to MS7 in both the selected locations.

From the results obtained, it can be claimed that:

- PCMS290 shows the best performance in both the selected locations, followed by MS7;

- the solution with parallel compression performs well for outdoor temperatures up to $33{ }^{\circ} \mathrm{C}$ and then its performance worsens due to the large amount of vapour which has to be sucked. The adoption of the auxiliary compressor is more beneficial in Valencia than in Athens due to its less warm weather trend;

- it is important to notice that a control system can more easily deal with the auxiliary compressor rather than with the mechanical subcooling. This limit could be partly overcome by adopting a fixed set-point temperature at the subcooler outlet;

- at very high outdoor temperature, the adoption of a mechanical subcooling is much more efficient than that of the parallel compression; 
- an economic analysis should be carried out in order to evaluated the payback period for all the evaluated R744 solutions and establish whether they could also be competitive in economic terms or not;

- an experimental campaign should be implemented in order to validate the results computed in this paper.

The only paper in which a similar comparison to the one attained in this study has been made by Polzot et al. (2015). Considering the difference in the assumptions made and in the operating conditions, the results are quite consistent.

The improvement by utilising $\mathrm{CO}_{2}$ is to large extent related to the avoidance of the direct emission as the power consumption of all the improved the systems is similar to that of the baseline. The exception is the conventional booster, which shows relatively high emissions in Athens. Improved design of the $\mathrm{CO}_{2}$ may make them even more competitive with HFC systems. 


\section{Acknowledgments}

Paride Gullo would like to thank the "Fondo Sociale Europeo in Friuli Venezia Giulia" for the economic support to the present research.

\section{References}

- Bella, B., Kaemmer, N., 2011. Experimental Performance of Carbon Dioxide Compressor with Parallel Compression. DKV-Tagung 2011, Aachen, Germany.

- BITZER, 2015. BITZER Software Version 6.4.3.1302 - Available at: <https://www.bitzer.de/websoftware/> [accessed 19.10.2015].

- Cecchinato, L., Corradi, M., Minetto, S., Chiesaro, P., 2007. An experimental analysis of a supermarket plant working with carbon dioxide as refrigerant. In: Proceedings of the $22^{\text {nd }}$ IIR International Congress of Refrigeration, Beijing, China.

- Chesi, A., Esposito, F., Ferrara, G., Ferrari, L., 2014. Experimental analysis of R744 parallel compression cycle. Applied Energy 135(C), 274-285. DOI: $10.1016 /$ j.apenergy.2014.08.087

- Chiarello, M., Girotto, S., Minetto, S., 2010. $\mathrm{CO}_{2}$ supermarket refrigeration system for hot climates. In: Proceedings of the $9^{\text {th }}$ IIR-Gustav Lorentzen Conference on Natural Refrigerants, Sydney, Australia.

- Da Ros, S., 2005. Optimisation of a Carbon Dioxide Transcritical Cycle with Flash-gas Removal. In: Proceedings of IIR International Conferences - Thermophysical properties and Transfer Processes of Refrigerants, Vicenza, Italy.

- Dorin, 2015. Dorin Software 15.06 - Available at: 〈http://www.dorin.com/en/Software/> [accessed 19.10.2015].

- EMERSON Climate Technologies, 2010. Refrigerant Choices for Commercial Refrigeration Finding the Right Balance. Technical Report No.: TGE124-091/E - Available at: <http://www.emersonclimate.com/> [accessed 19.10.2015].

- European Commission, 2014. Regulation (EU) No 517/2014 of the European Parliament and of the Council of $16^{\text {th }}$ April 2014 on fluorinated greenhouse gases and repealing Regulation (EC) No 842/2006.

- F-Chart Software, 2015a. Engineering Equation Solver (EES), Academic Professional version 9.908 - Available at: 〈http://www.fchart.com/ees/> [accessed 19.10.2015].

- F-Chart Software, 2015b. Engineering Equation Solver Manual, Madison (USA) - Available at: <http://www.fchart.com/assets/downloads/ees_manual.pdf $>$ [accessed 19.10.2015].

- Fazelpour, F., Morosuk, T., 2014. Exergoeconomic analysis of carbon dioxide transcritical refrigeration machines. International Journal of Refrigeration 38, 128-139. DOI: 10.1016/j.ijrefrig.2013.09.016

- Ge, Y.T., Tassou, S.A., 2011. Thermodynamic analysis of transcritical $\mathrm{CO}_{2}$ booster refrigeration systems in supermarket. Energy Conversion and Management 52(4), 1868-1875. DOI: $10.1016 /$ j.enconman.2010.11.015

- Girotto, S., Minetto, S., Nekså, P., 2004. Commercial refrigeration system using $\mathrm{CO}_{2}$ as the refrigerant. International Journal of Refrigeration 27(7), 717-723. DOI: 10.1016/j.ijrefrig.2004.07.004

- Gullo, P., Elmegaard, B., Cortella, G., 2015. Energetic, Exergetic and Exergoeconomic Analysis of $\mathrm{CO}_{2}$ Refrigeration Systems Operating in Hot Climates. In: Proceedings of the $28^{\text {th }}$ International Conference on Efficiency, Cost, Optimization Simulation and Environmental Impact of Energy Systems, Pau, France. 
- Hafner, A., Hemmingsen, A.K., 2015. R744 refrigeration technologies for supermarkets in warm climates. In: Proceedings of the $24^{\text {th }}$ IIR International Congress of Refrigeration, Yokohama, Japan.

- Hafner, A., Hemmingsen, A.K., Van de Ven, A., 2014a. R744 refrigeration system configurations for supermarkets in warm climates. In: Proceedings of the $3^{\text {rd }}$ IIR International Conference on Sustainability and Cold Chain, London, United Kingdom.

- Hafner, A., Hemmingsen, A.K., Nekså, P., 2014b. System configuration for supermarkets in warm climates applying R744 refrigeration technologies - Case studies of selected Chinese cities. In: Proceedings of the $11^{\text {th }}$ IIR Gustav Lorentzen Conference on Natural Refrigerants, Hangzhou, China.

- International Energy Agency, 2013. $\mathrm{CO}_{2}$ emissions from fuel combustion Highlights (2013 Edition). OECD/IEA, Paris, France. - Available at: 〈https://www.iea.org/> [accessed 19.10.2015].

- Kim, M.-H., Pettersen, J., Bullard, C.W., 2004. Fundamental process and system design issues in $\mathrm{CO}_{2}$ vapor compression systems. Progress in Energy and Combustion Science 30(2), 119174. DOI: $10.1016 /$ j.pecs.2003.09.002

- Llopis, R., Cabello, R., Sánchez, D., Torrella, E., 2015a. Energy improvement of $\mathrm{CO}_{2}$ transcritical refrigeration cycles using dedicated mechanical subcooling. International Journal of Refrigeration 55, 129-141. DOI: $\underline{\text { 10.1016/j.ijrefrig.2015.03.016 }}$

- Llopis, R., Sánchez, D., Sanz-Kock, C., Cabello, R., Torrella, E., 2015b. Energy and environmental comparison of two-stage solutions for commercial refrigeration at low temperature: Fluids and systems. Applied Energy 138, 133-142. DOI: $\underline{10.1016 / j . a p e n e r g y .2014 .10 .069}$

- Minetto, S., Girotto, S., Salvatore, M., Rossetti, A., Marinetti, S., 2014. Recent installations of $\mathrm{CO}_{2}$ supermarket refrigeration system for warm climates: data from field. In: Proceedings of the $3^{\text {rd }}$ IIR International Conference on Sustainability and Cold Chain, London, United Kingdom.

- Minetto, S., Cecchinato, L., Corradi, M., Fornasieri, E., Zilio, C., 2005. Theoretical and Experimental Analysis of a $\mathrm{CO}_{2}$ Refrigerating Cycle with Two-Stage Throttling and Suction of the Flash Vapour by an Auxiliary Compressor. In: Proceedings of IIR International Conferences - Thermophysical Properties and Transfer Processes of Refrigerants, Vicenza, Italy.

- Polzot, A., D’Agaro, P., Gullo, P., Cortella, G., 2015. Water storage to improve the efficiency of $\mathrm{CO}_{2}$ commercial refrigeration systems. In: Proceedings of the $24^{\text {th }}$ IIR International Congress of Refrigeration, Yokohama, Japan.

- Qureshi, B.A., Zubair, S.M., 2013. Mechanical sub-cooling vapor compression systems: Current status and future directions. International Journal of Refrigeration 36(8), 2097-2110. DOI: $10.1016 /$ j.ijrefrig.2013.07.026

- Remund, J., Lang, R., Kunz, S., 2014. Meteonorm, Meteotest, Bern (Switzerland).

- Sanz-Kock, C., Llopis, R., Sánchez, D., Cabello, R., Torrella E., 2014. Experimental evaluation of a R134a/ $/ \mathrm{CO}_{2}$ cascade refrigeration plant. Applied Thermal Engineering 73(1), 41-50. DOI: $\underline{\text { 10.1016/j.applthermaleng.2014.07.041 }}$

- Sarkar, J., Agrawal, N., 2010. Performance optimization of transcritical $\mathrm{CO}_{2}$ cycle with parallel compression economization. International Journal of Thermal Sciences 49(5), 838-843. DOI: $\underline{10.1016 / \text { i.ijthermalsci.2009.12.001 }}$

- Sawalha, S., Karampour, M., Rogstam, J., 2015. Field measurements of supermarket refrigeration systems. Part I: Analysis of $\mathrm{CO}_{2}$ trans-critical refrigeration systems. Applied Thermal Engineering 87, 633-647. DOI: 10.1016/j.applthermaleng.2015.05.052 
- Shilliday, J.A., 2012. Investigation and optimisation of commercial refrigeration cycles using the natural refrigerant $\mathrm{CO}_{2}$ [Ph.D. dissertation]. London, United Kingdom: Brunel University Available at: <http://bura.brunel.ac.uk/handle/2438/7454/> [accessed 19.10.2015].

- Souza, L., Antunes, A., Mendoza, O., Bandarra Filho, E., 2015. Experimental evaluation of a cascade refrigeration system operating with R744/R134a. In: Proceedings of the $24^{\text {th }}$ IIR International Congress of Refrigeration, Yokohama, Japan.

- The Australian Institute of Refrigeration, Air Conditioning and Heating, 2012. Methods of calculating Total Equivalent Warming Impact (TEWI) 2012. - Available at: <http://www.airah.org.au/> [accessed 19.10.2015].

- Thornton, J.W., Klein, S.A., Mitchell, J.W., 1994. Dedicated Mechanical Subcooling Design Strategies for Supermarket Applications. International Journal of Refrigeration 17(8), 508-515. DOI: $\underline{10.1016 / 0140-7007(94) 90026-4}$ 
FIG. 1

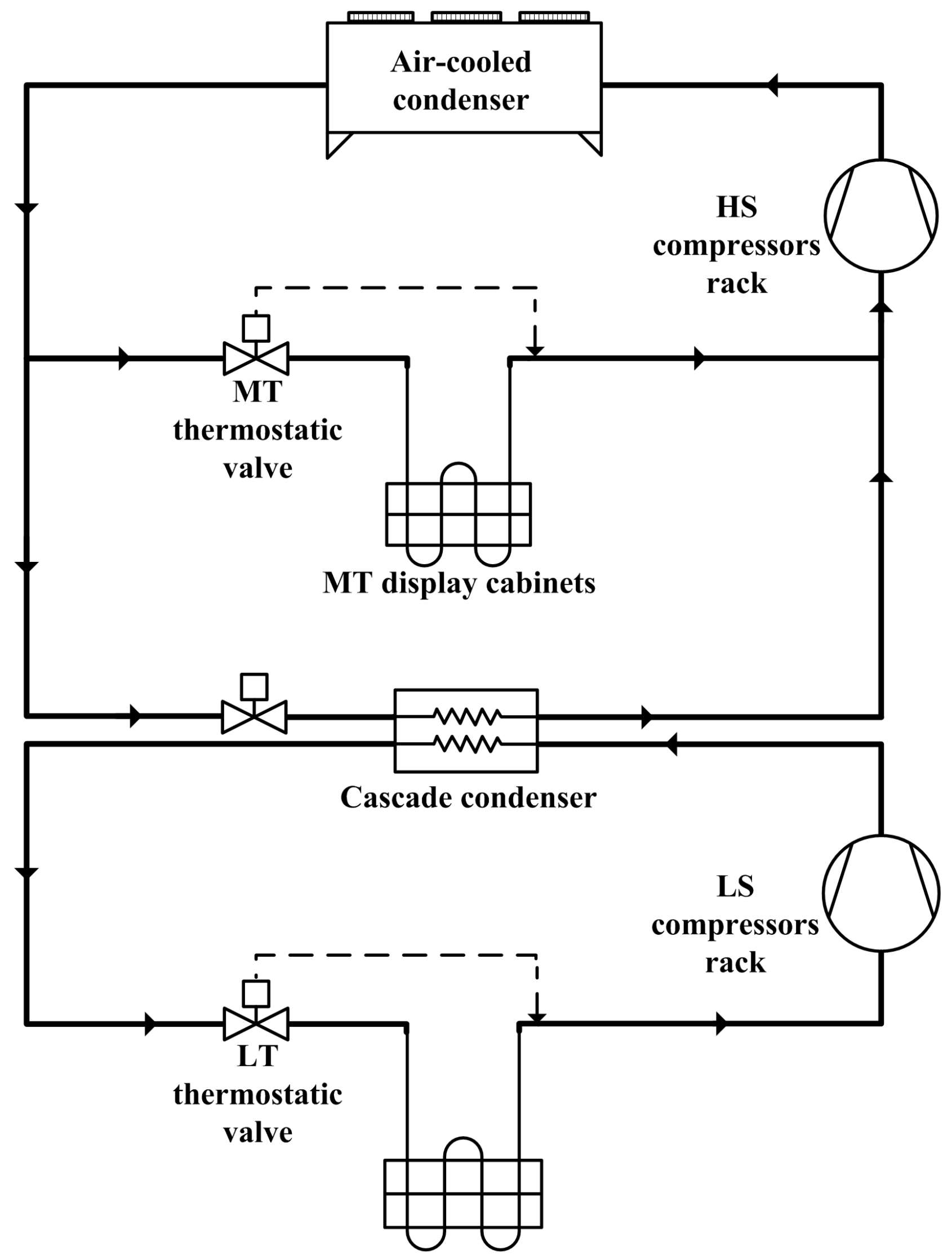

LT display cabinets 
FIG. 2

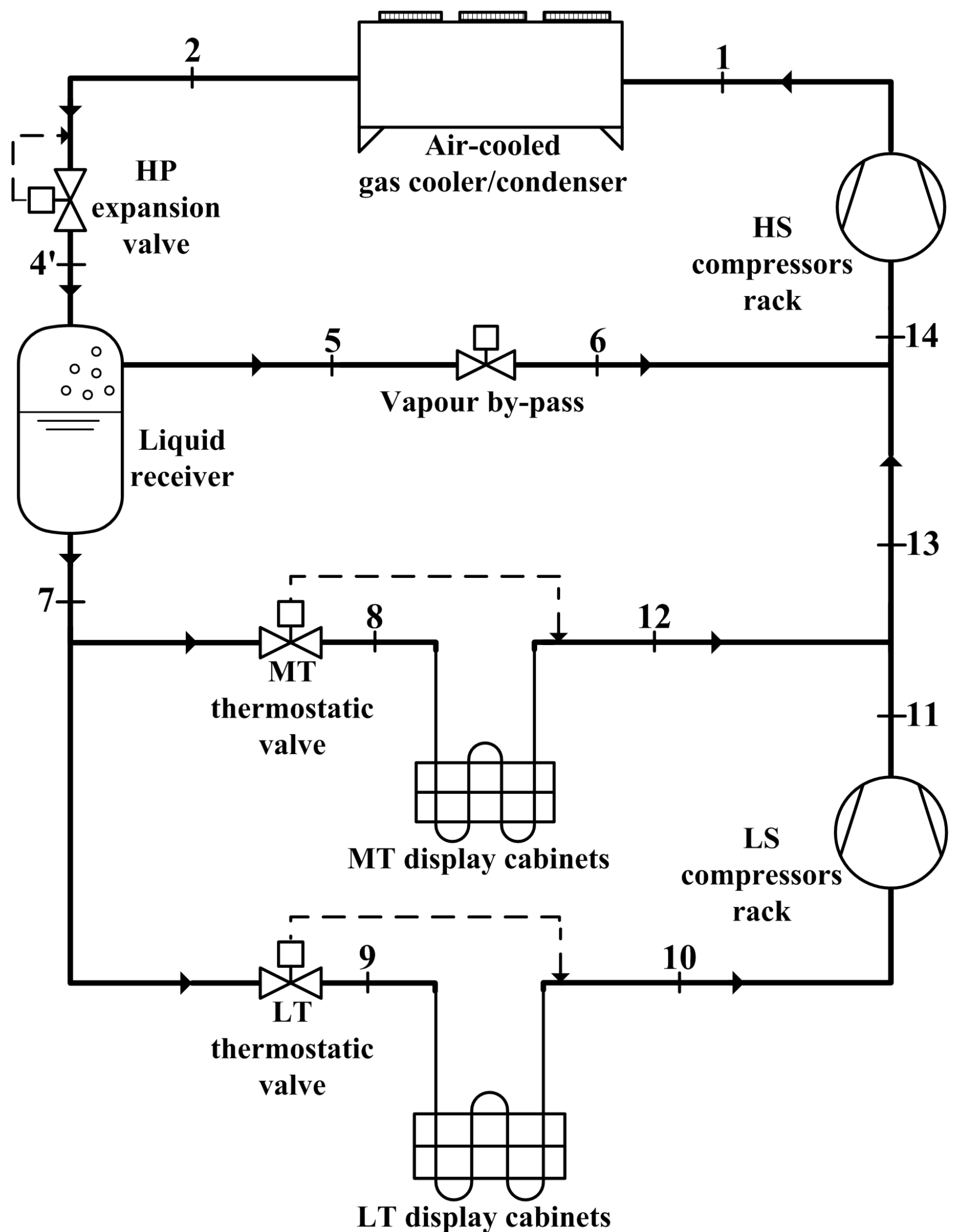


FIG. 3

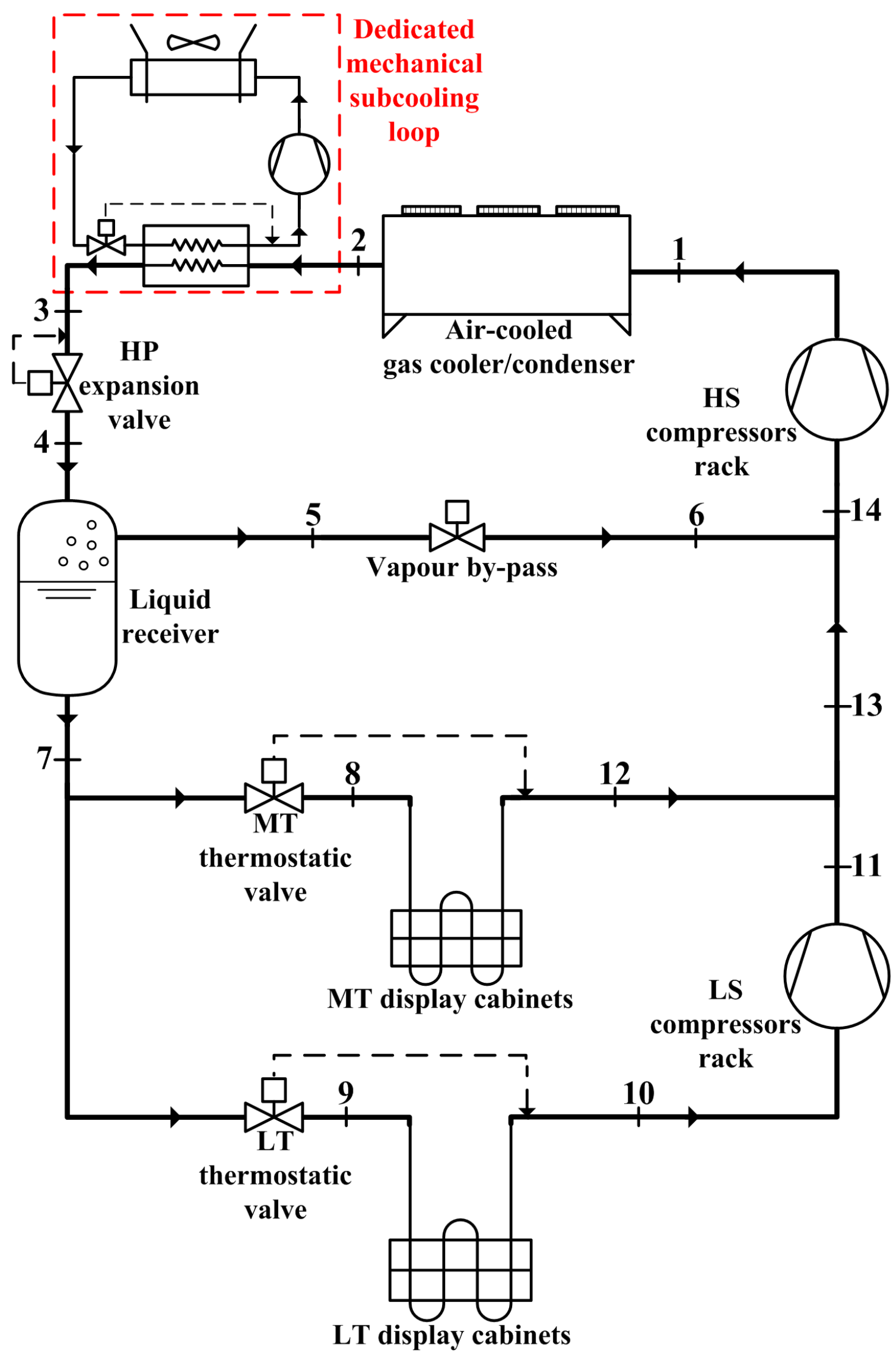




\section{FIG. 4}

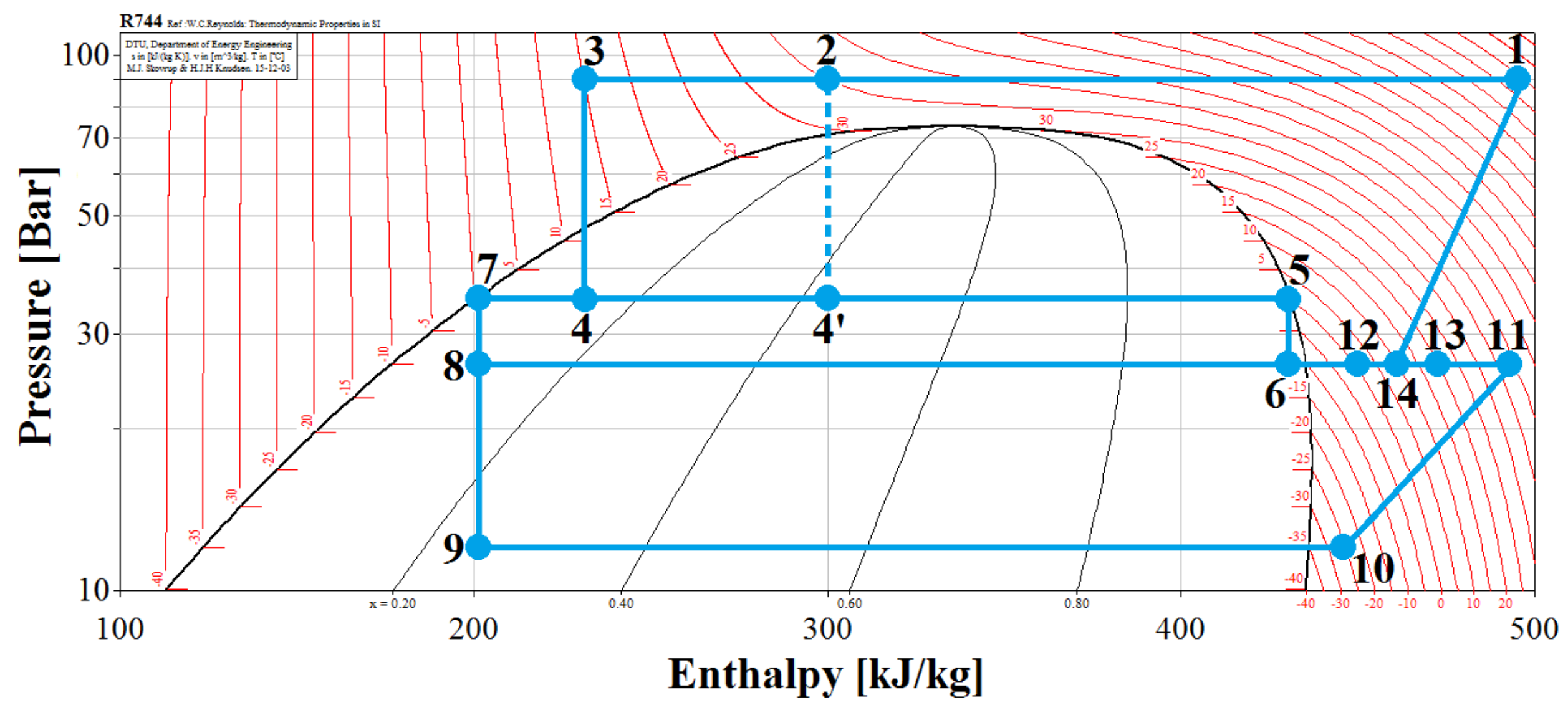


FIG. 5

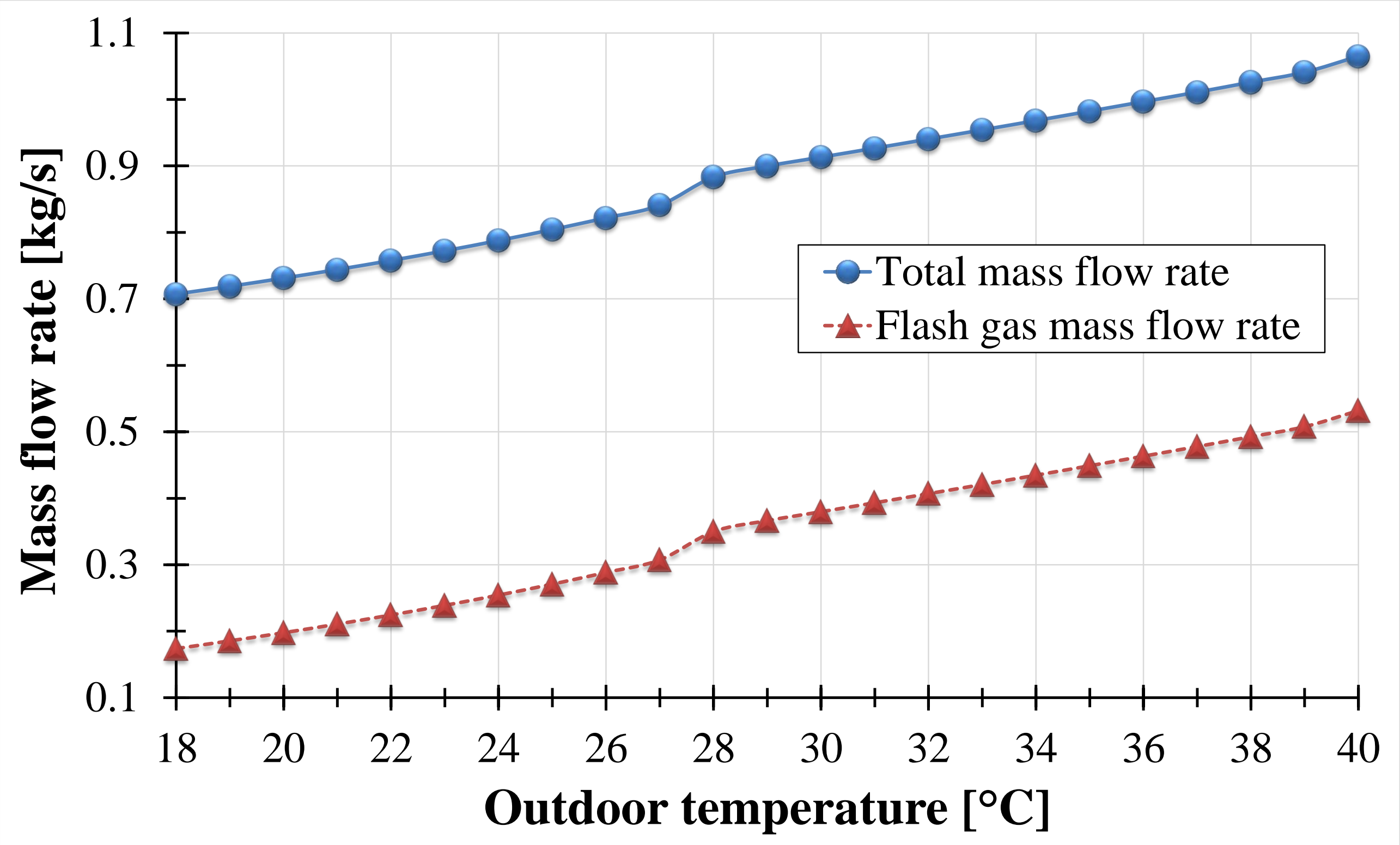


FIG. 6

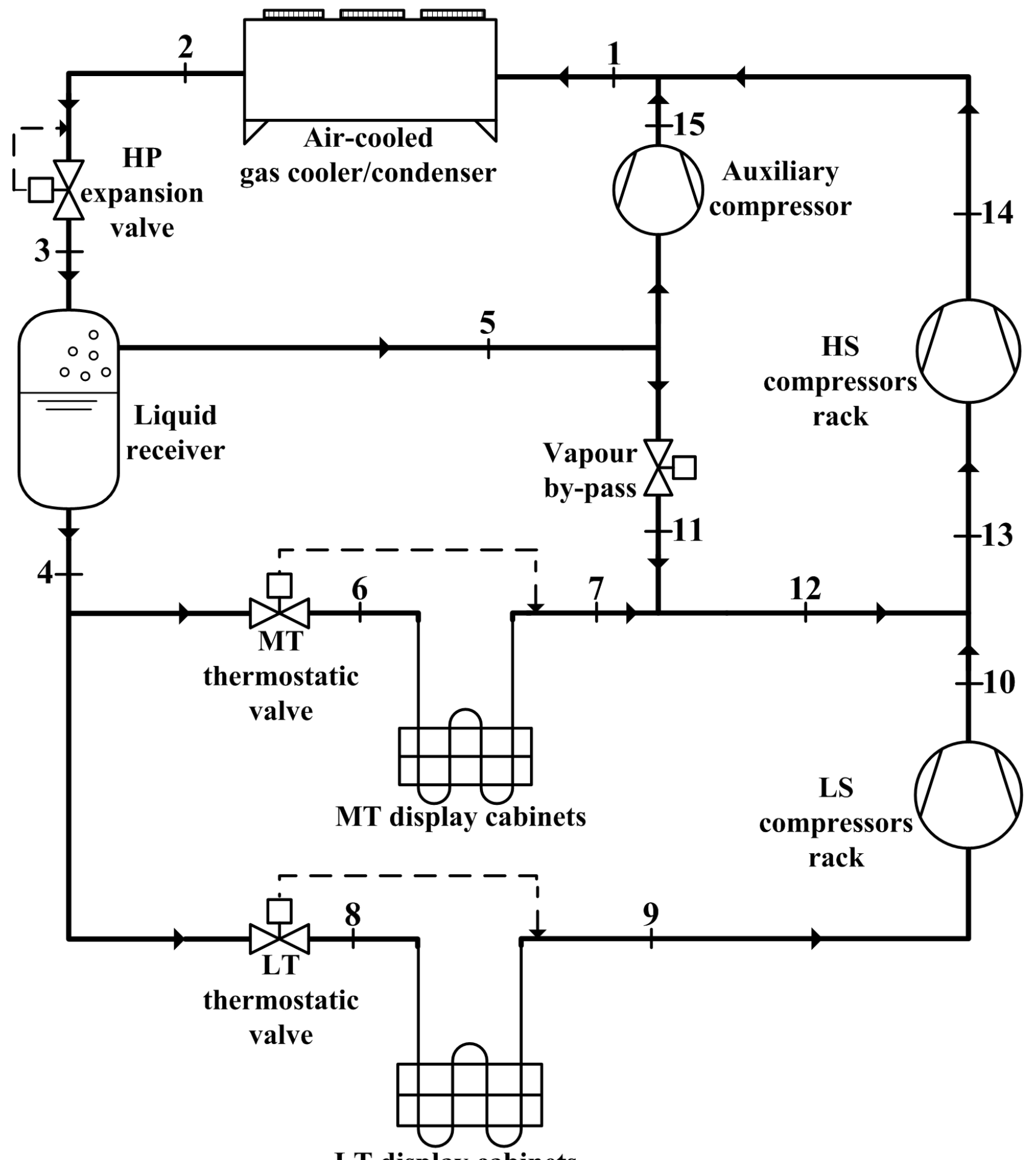

LT display cabinets 


\section{FIG. 7}

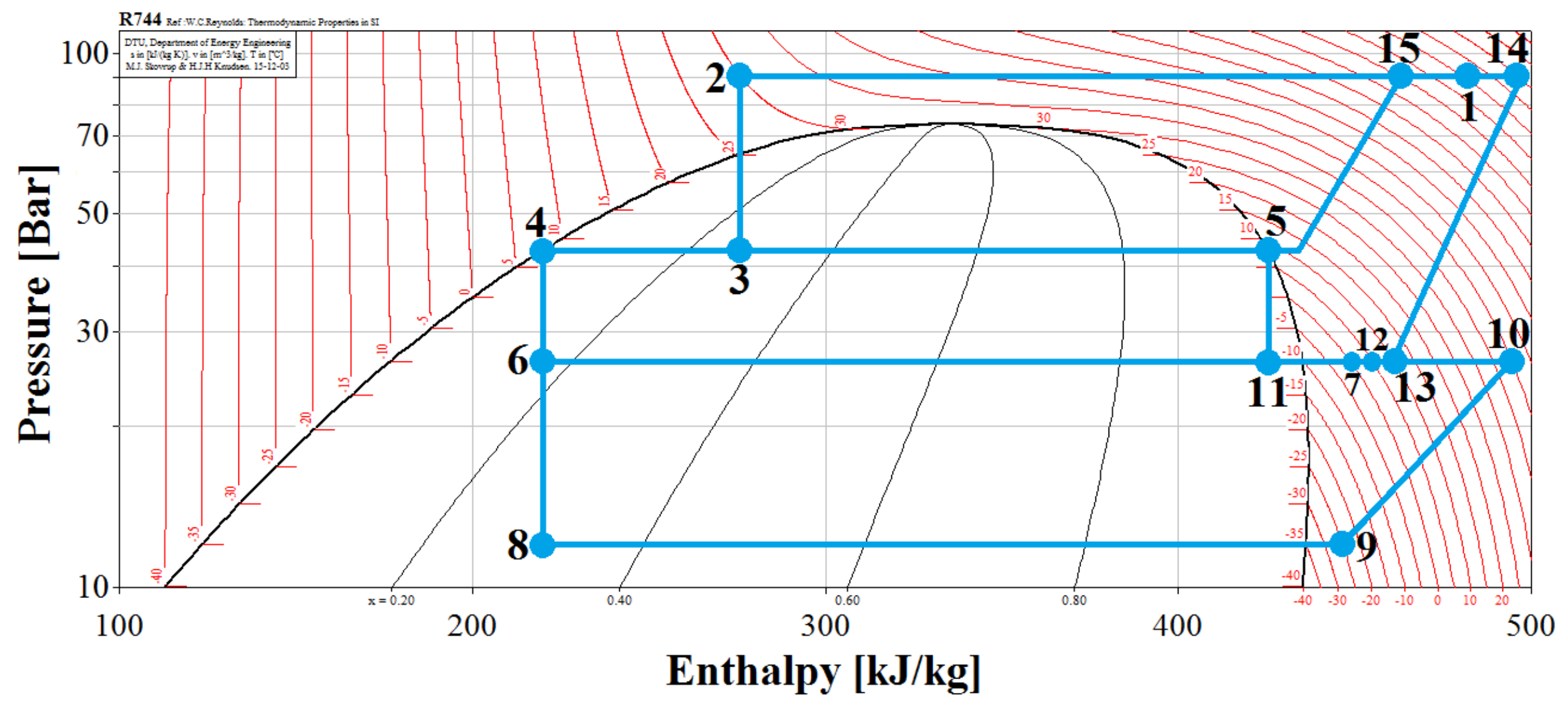


FIG. 8

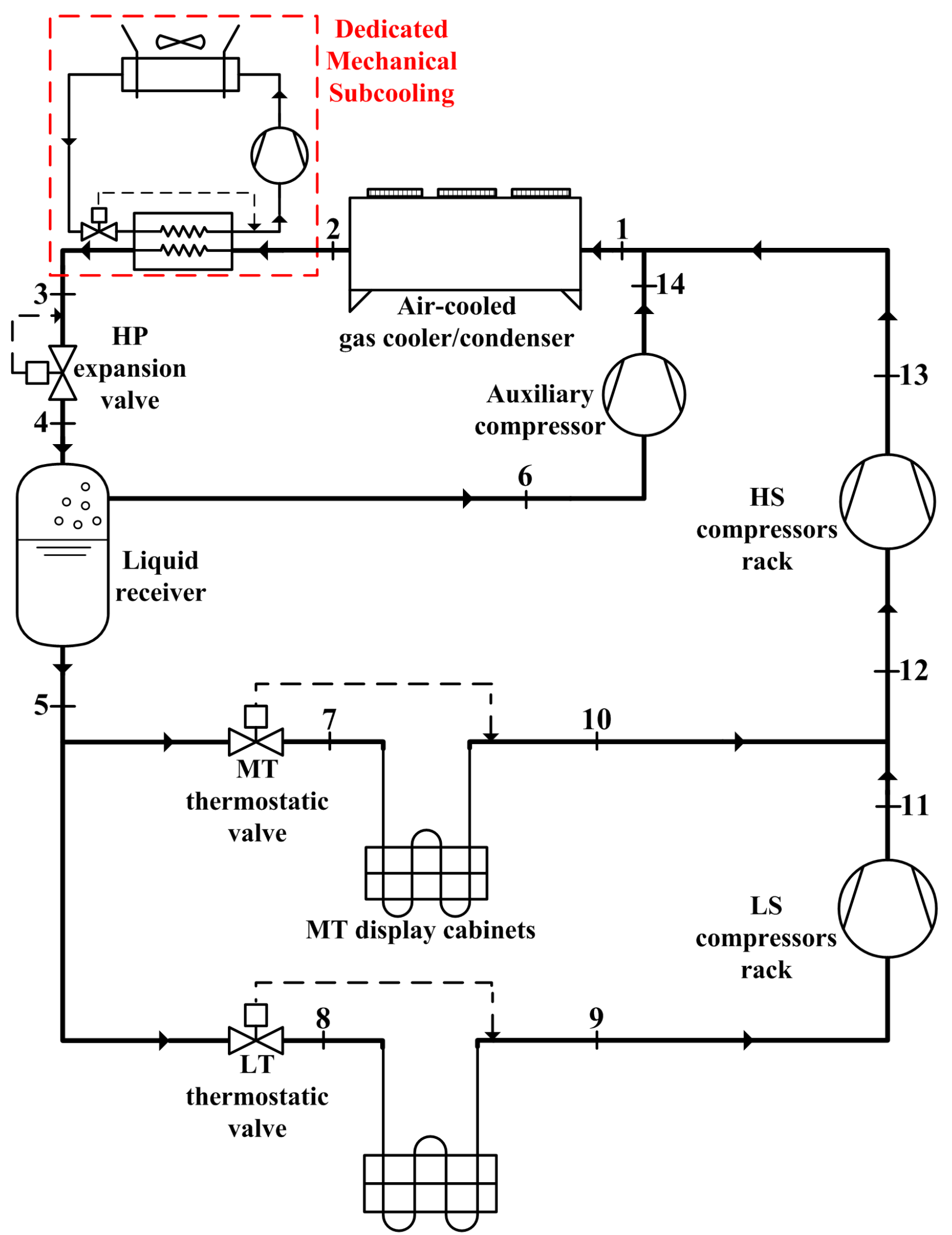

LT display cabinets 
FIG. 9

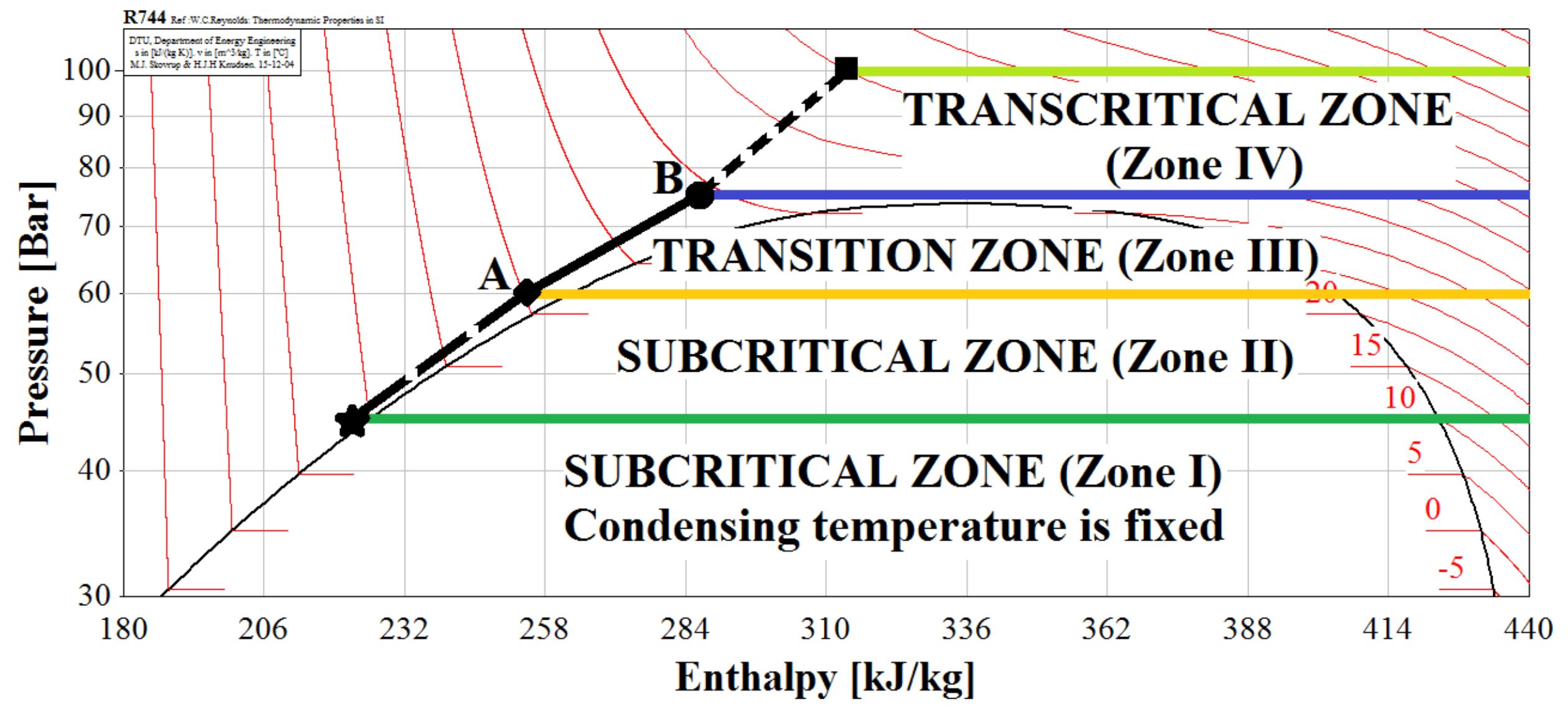


FIG. 10

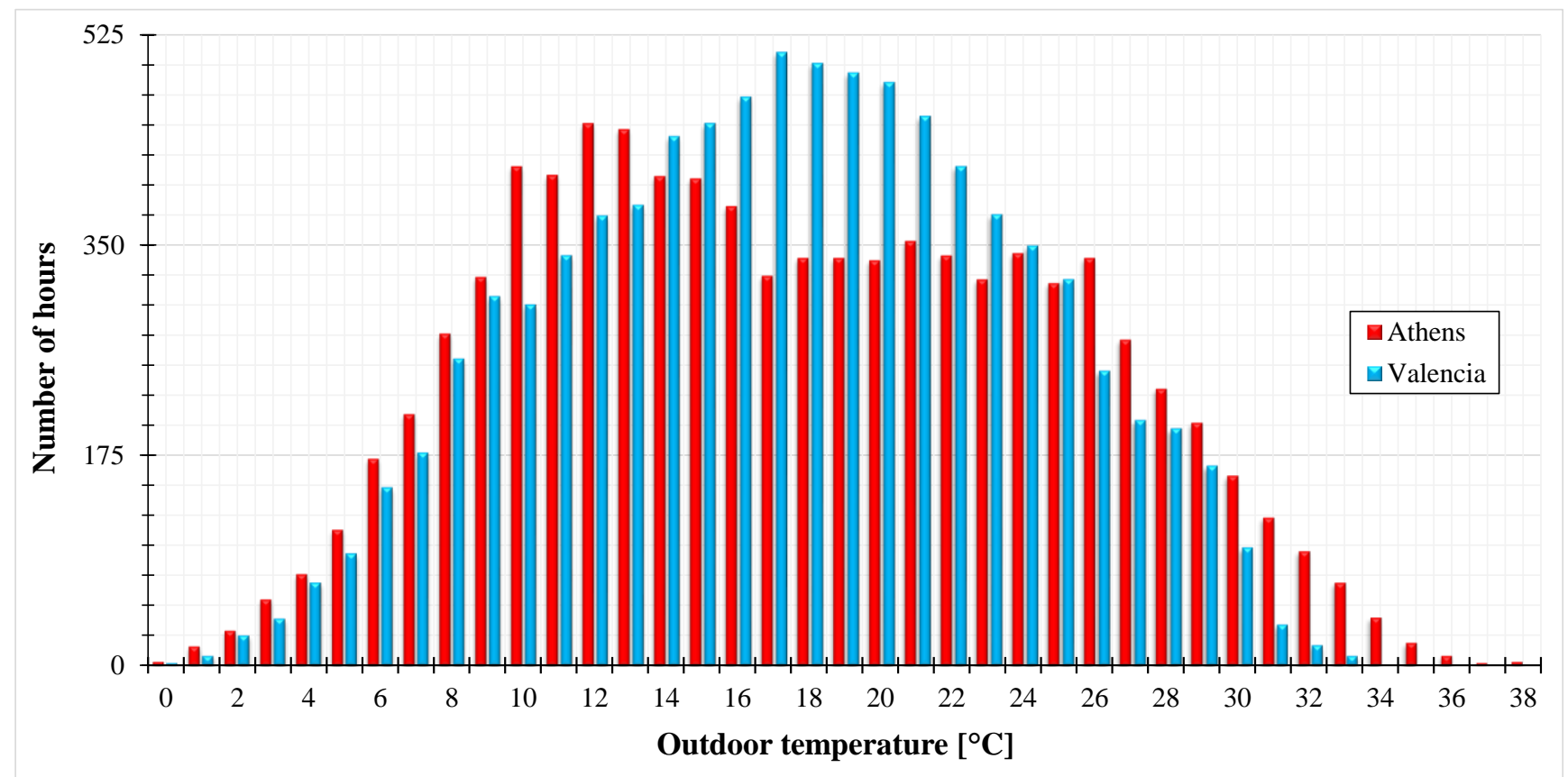


FIG. 11

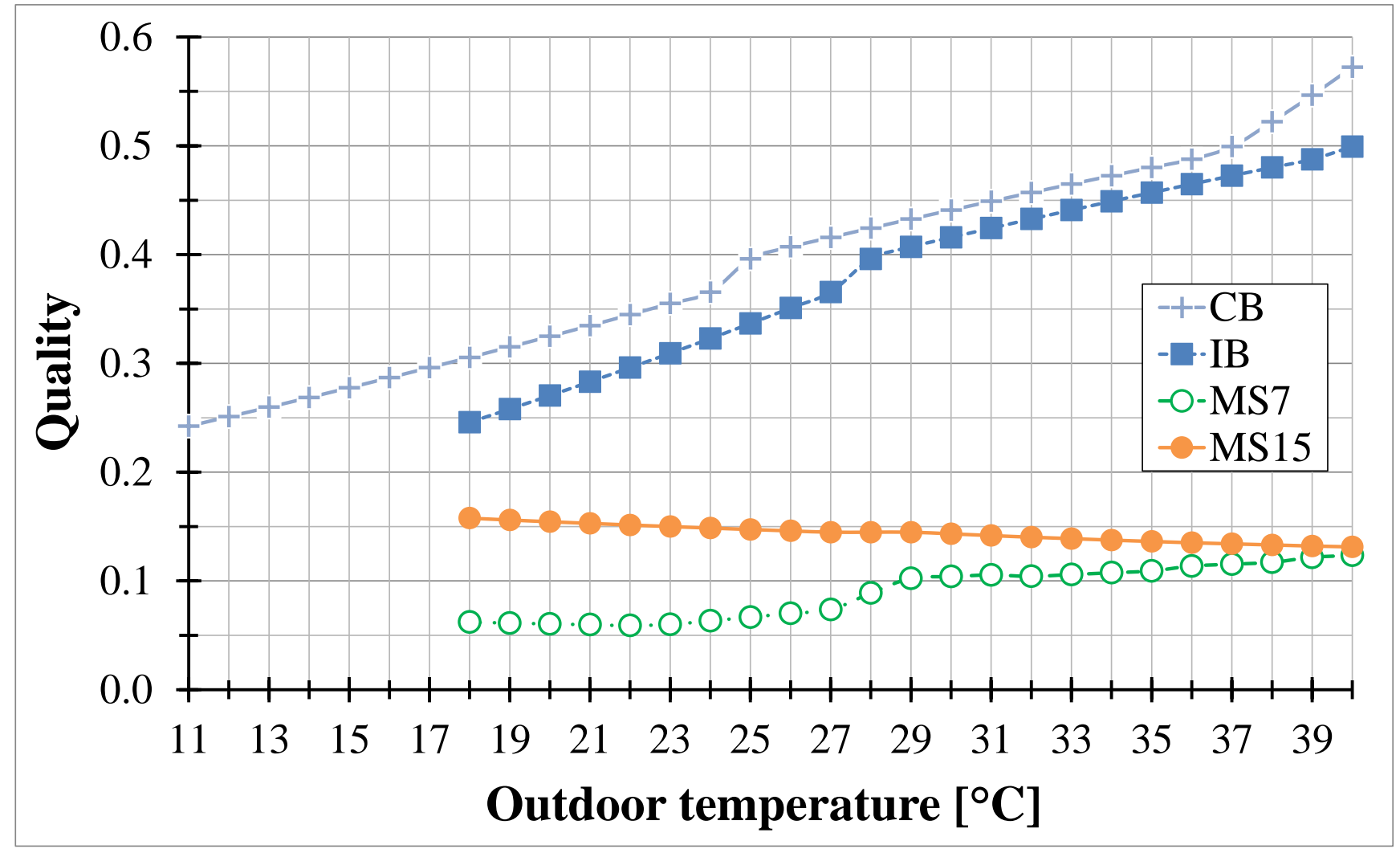


FIG. 12

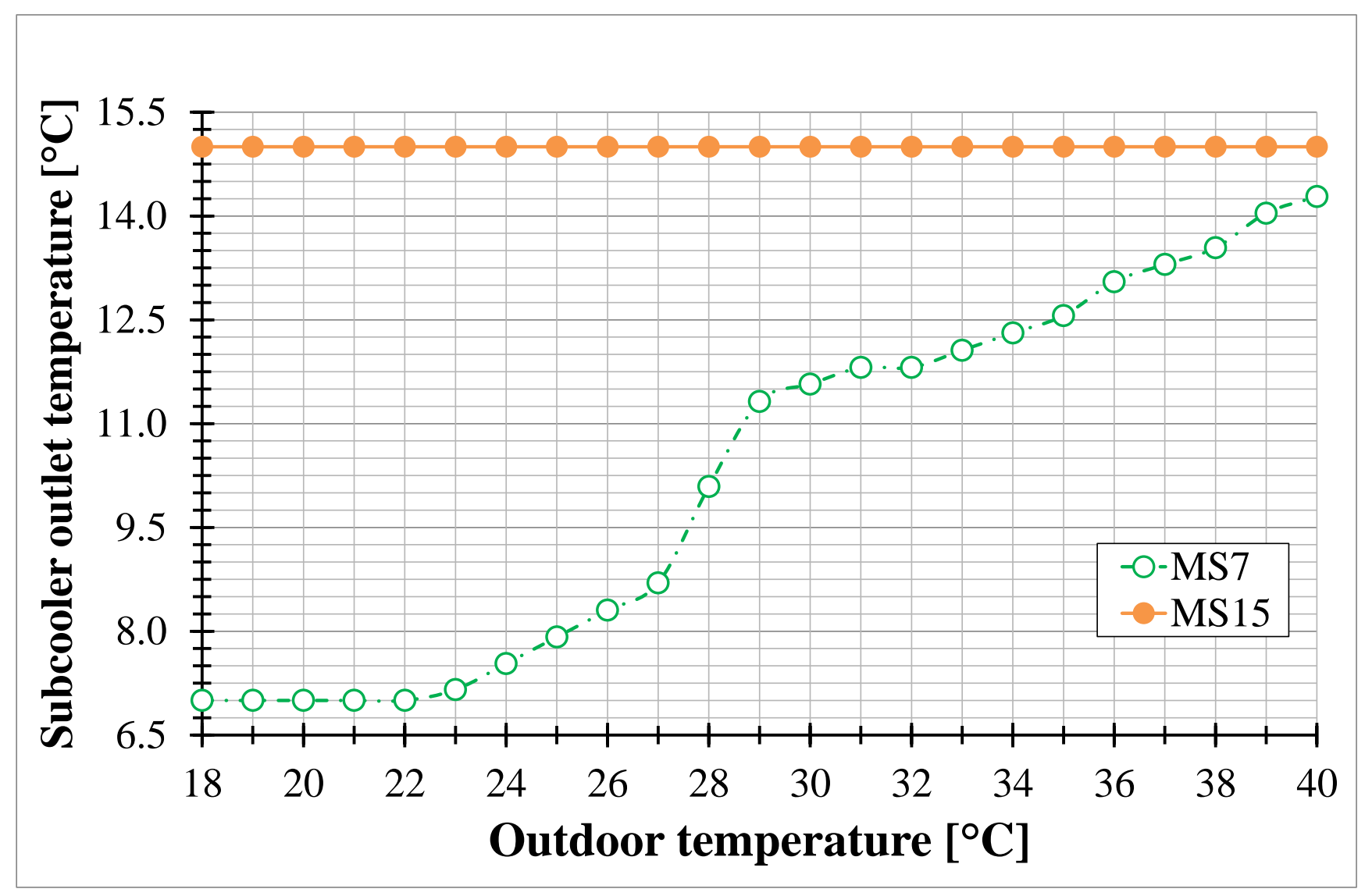




\section{FIG. 13}

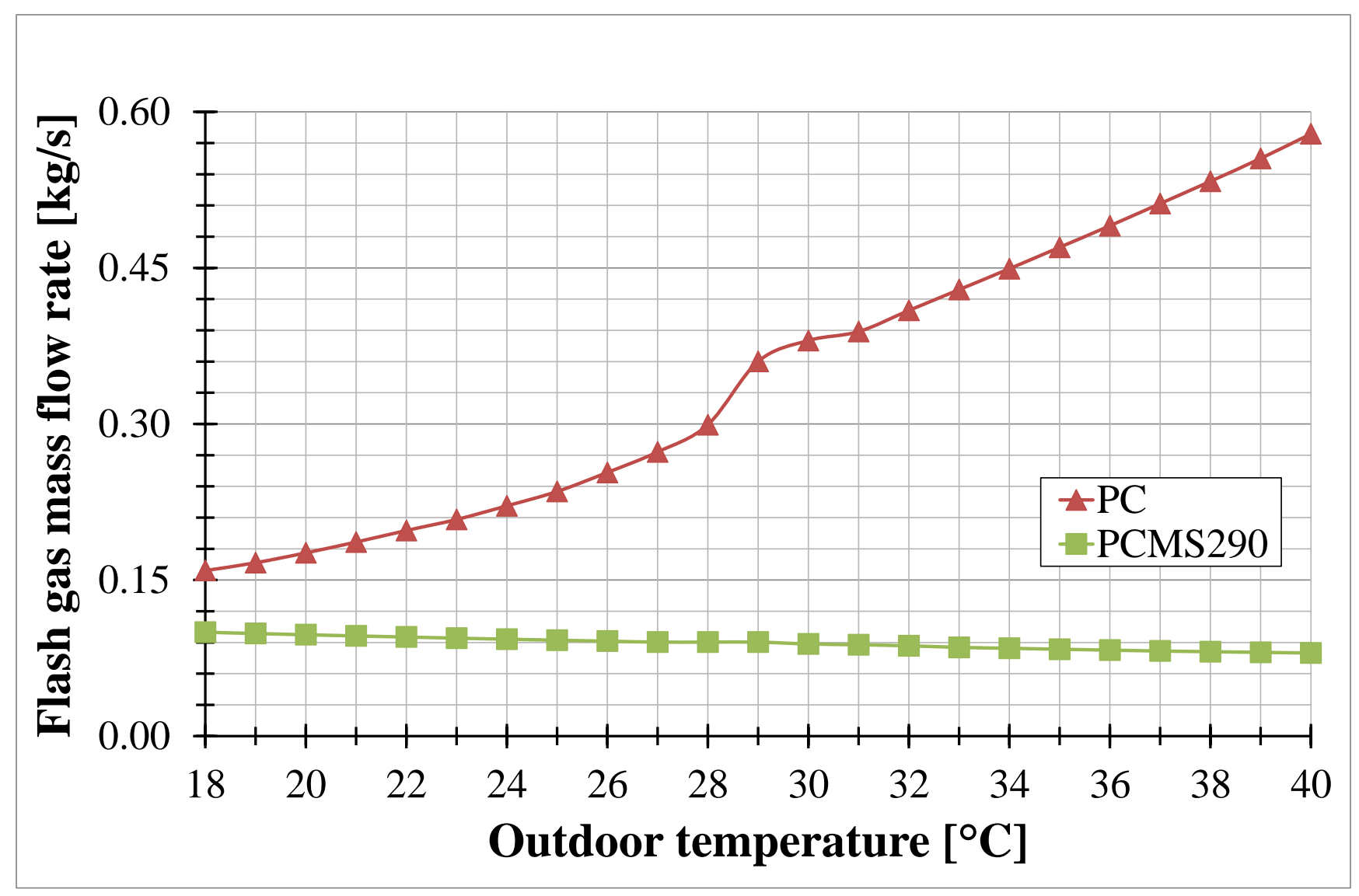


FIG. 14

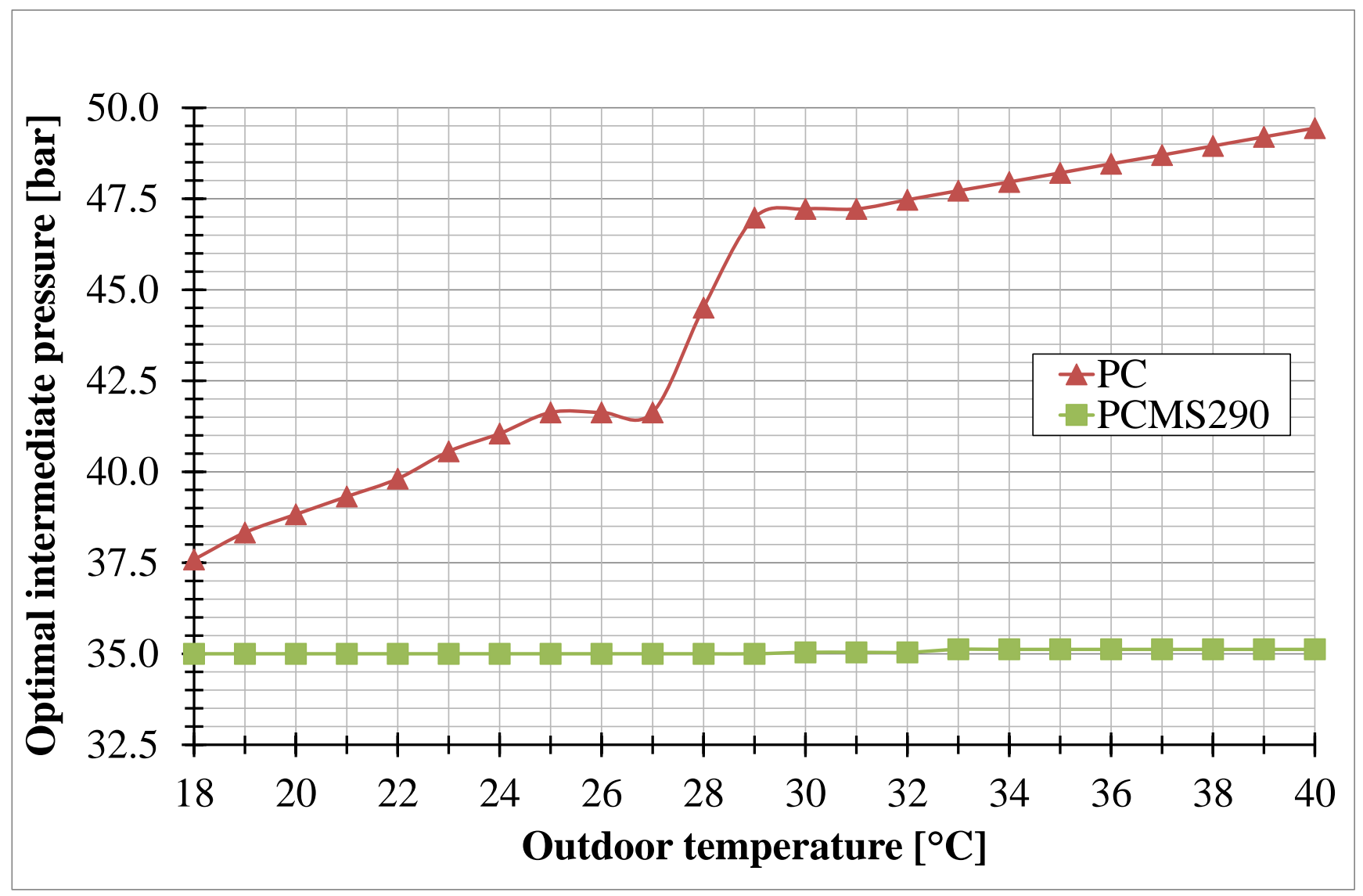


FIG. 15

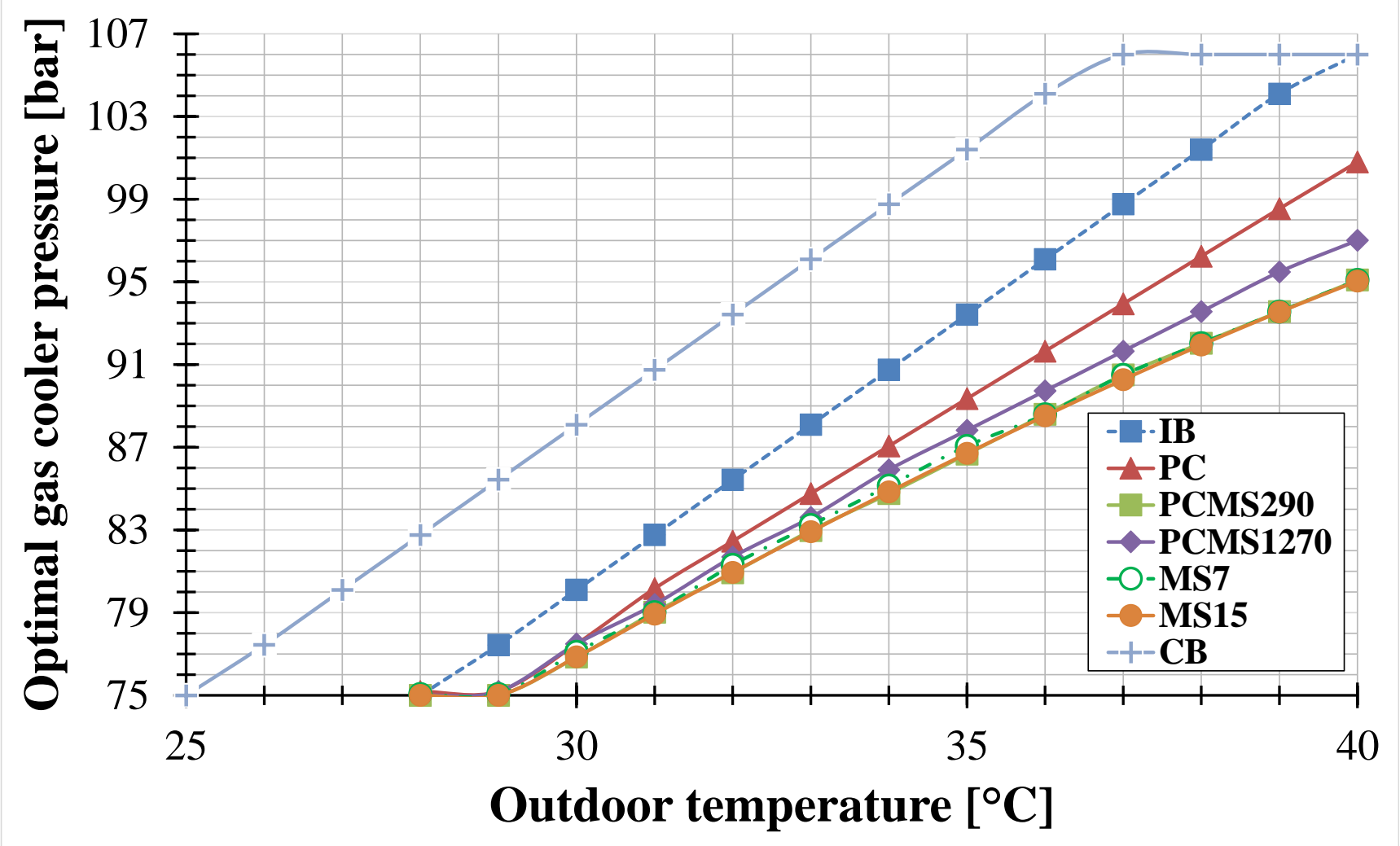




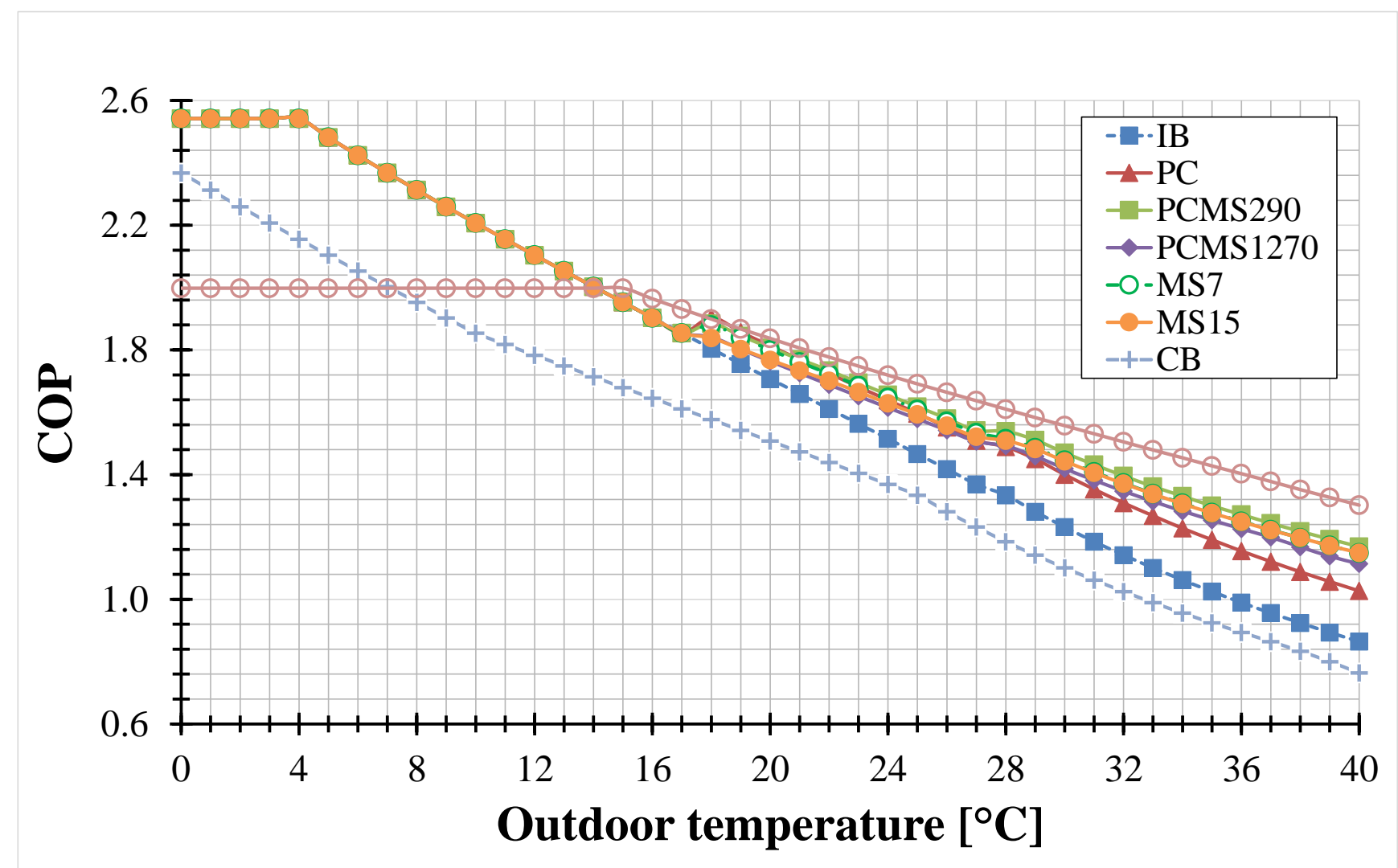


FIG. 17

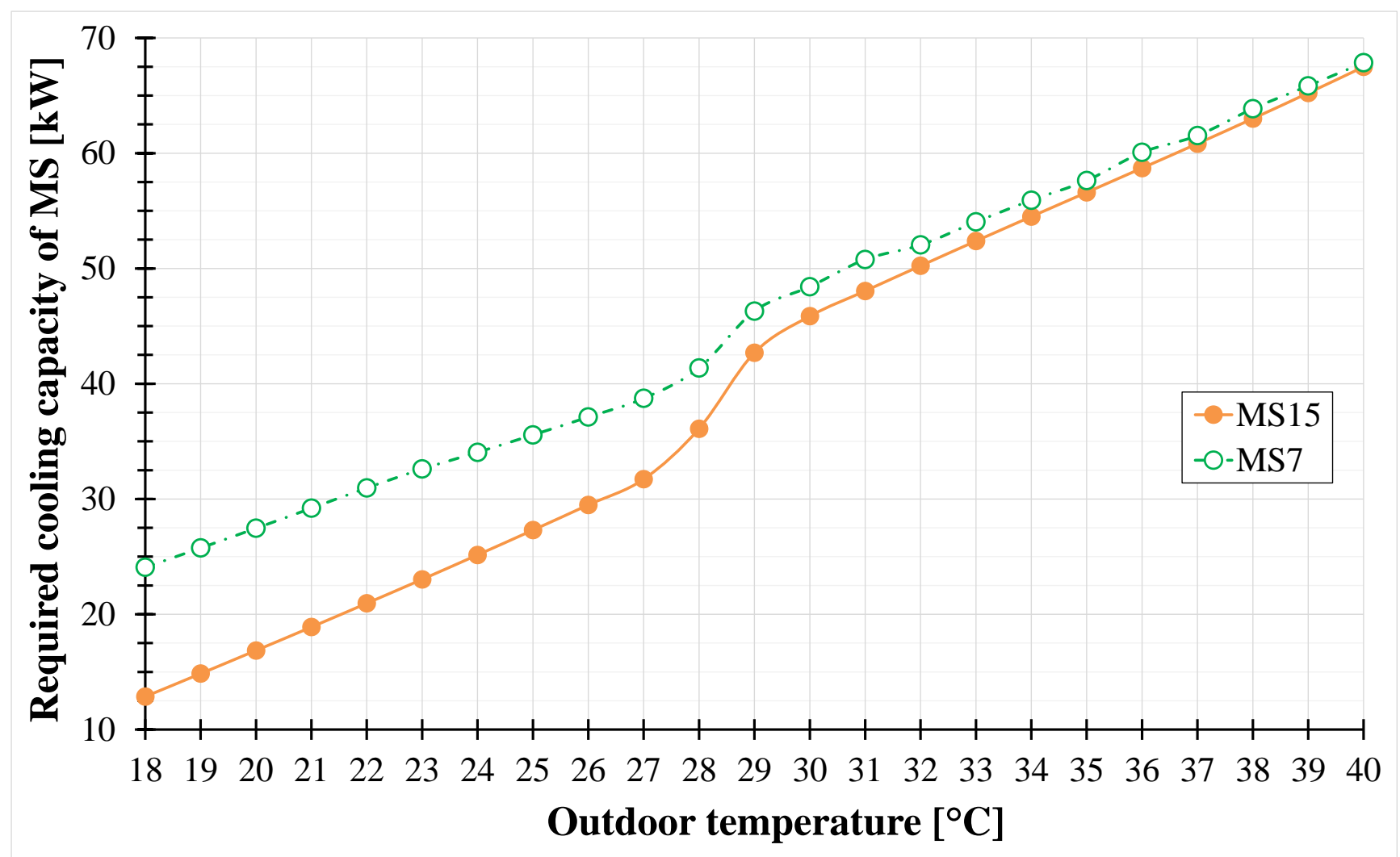




\author{
Figure
Click here to download Electronic Annexes: JIJR-D-15-00514_Charts.xIsx
}

